\title{
ENCUESTA SOBRE DERECHOS FUNDAMENTALES
}

El Consejo de Redacción de esta Revista ha debatido en varias ocasiones sobre la oportunidad de dedicar uno de nuestros números monográficos a determinados derechos fundamentales. Y por unas u otras razones la decisión se ha ido posponiendo a favor de otros temas.

Ahora, al cumplir Teoría y Realidad Constitucional diez años de vida y dar a luz su número 20, no hemos querido demorar más la publicación de este número monográfico que en tan señalada ocasión hemos deseado que aborde el ancho ámbito de los Derechos Fundamentales a los que la Constitución de 1978 dedica un extenso Título I, que pese al tiempo transcurrido sigue mereciendo en la doctrina una valoración que, en términos generales, es francamente positiva.

Es innecesario constatar la centralidad de los derechos fundamentales en el orden constitucional. No en vano formaban parte del núcleo de la idea de Constitución en el primer constitucionalismo francés y el artículo 16 de la Declaración de derechos del hombre y del ciudadano de 1789, como todos sabemos, es la mejor prueba de ello. Nuestra Constitución en su capital artículo 10 los concibe acertadamente como fundamento del orden político y de la paz social.

Descartada, tras amplio debate en la Ponencia de la Comisión constitucional del Congreso, la opción de una tabla de derechos fundamentales abreviada y/o contenedora de un mero reenvío a la Declaración Universal de Derechos Humanos y a otros acuerdos fundamentales sobre esta materia, se eligió el camino de articular un detallado listado de cuantos derechos y deberes fundamentales debían ser objeto de constitucionalización. Esta opción tenía naturalmente su dimensión en técnica legislativa, pero estaba esencialmente provista de la voluntad de cargar la voluntad del constituyente en la proclamación de unos derechos y libertades que durante cuarenta años habían sido sistemáticamente olvidados y frecuentemente vulnerados. El carácter garantista de la técnica de orfebre puntilloso utilizada por las Cortes constituyentes es fácilmente entendible y merecedor de aplauso, sobre todo a la vista de que ha facilitado pautas seguras al legislador ordinario, al Tribunal Constitucional y a los órganos de justicia ordinaria.

Ciertamente, el legislador ordinario desde la temprana fecha de 1979 desplegó un esfuerzo sistemático para efectuar un desarrollo legislativo de ta- 
les derechos a la altura de las exigencias de la Constitución y del tiempo en que nos corresponde vivir, aunque con alguna laguna como la del derecho de huelga, aún no colmada. Por su parte, el Tribunal Constitucional ha elaborado una amplísima jurisprudencia sobre la materia, vía unos recursos de amparo que recientemente han sido objeto de un importante recorte legislativo mediante la última reforma de la LOTC, quizás precisamente porque ya a estas alturas el TC ha dotado a los derechos fundamentales constitucionalizados de un desarrollo dogmático particularmente preciso y, en ocasiones, muy casuístico y puede pensarse que nuestro alto intérprete de la Carta Magna ha glosado suficientemente el Título I de la CE y su labor al respecto requiere ahora de menor intensidad y esfuerzo.

Naturalmente, este número monográfico — para cuya confección el Consejo de Redacción ha pasado el duro trance de tener que seleccionar de entre el numeroso material de calidad recibido el publicable en el limitado número de páginas de que disponemos- lo abrimos, según es ya inveterada costumbre, con una encuesta. Y a tal efecto nos hemos dirigido, de entre tantos buenos especialistas en la materia a algunos de los más relevantes expertos, no solo Catedráticos de Derecho constitucional, sino también de Filosofía del Derecho. Con especial interés hemos recabado las respuestas de algunos constituyentes que tuvieron un especial protagonismo en la confección del Título I de la Constitución, como es el caso del Prof. Peces Barba y del Académico Miguel Herrero de Miñón, a quien una inoportuna operación quirúrgica le ha impedido remitirnos unas cuartillas en plazo.

Sólo nos resta añadir que el carácter amplio, si se quiere impreciso, de las preguntas es intencionado y buscaba que quienes nos honrasen con sus respuestas pudiesen reflejar sus puntos de vista con particular libertad, ya que las preguntas sólo aspiraban a ser excusas para que nuestros invitados desarrollasen su visión del tratamiento constitucional de los derechos fundamentales libérrimamente y sin encorsetamiento alguno. Desde aquí les reiteramos nuestro sincero agradecimiento por su valiosa colaboración.

\section{ENCUESTADOS}

Luis Aguiar de Luque, Catedrático de Derecho Constitucional, Universidad Carlos III de Madrid.

Luis María Díez-Picazo, Catedrático de Derecho Constitucional, Universidad de Castilla La Mancha.

Ángel Gómez Montoro, Catedrático de Derecho Constitucional, Universidad de Navarra.

Gregorio Peces-Barba Martínez, Catedrático de Filosofía del Derecho, Universidad Carlos III de Madrid.

Juan José Solozábal Echavarría, Catedrático de Derecho Constitucional, Universidad Autónoma de Madrid. 


\section{LA CONSTITUCIÓN DE 1978 Y LOS DERECHOS Y DEBERES FUNDAMENTALES}

1. ¿Qué opinión global mantiene sobre el tratamiento que nuestra Constitución dio en 1978 a los derechos y deberes fundamentales?

\section{LUIS AGUIAR DE LUQUE}

La Constitución de 1978, como es sobradamente conocido, fue inicialmente redactada por una ponencia integrada por siete significados juristas, varios de ellos catedráticos de Teoría del Estado y Derecho Constitucional, alguno de los cuales reputado especialista precisamente en la materia "derechos humanos" de acuerdo con la terminología de la época. Esta cualificada formación de los redactores del primer anteproyecto (y que, a mayor abundamiento, en buena medida se mantendría en las restantes fases del proceso toda vez que varios parlamentarios constituyentes provenían del mundo académico o de cualificadas profesiones jurídicas) debió probablemente influir (e influir positivamente) en la elaboración de la tabla de derechos que contiene el Título I, dándole un claro "tono" académico perceptible en varios aspectos.

Por un lado la declaración de derechos es una clara expresión del estado de desarrollo de la teoría jurídica de los derechos fundamentales en el último tercio del siglo xx, que, como es sabido, configura éstos con una doble dimensión: derechos "resistentes" a las mayorías legislativas (por emplear la afortunada expresión de Dworkin) y derechos que en su dimensión subjetiva gozan de una protección reforzada, el recurso de amparo ante el Tribunal Constitucional; en esta misma línea, la estructura lógica de los diferentes derechos que se consagran, así como la secuencia de los enunciados de dicho Título conforman un hilo conductor coherente en los planos jurídico e ideológico, arrancando con los derechos de signo marcadamente individualista y carácter más tradicional (igualdad, derecho a la vida, inviolabilidad del domicilio, etc), continúa con los derechos que protegen la dimensión social y ciudadana del individuo (libertades de expresión, asociación o sufragio), consagra después los derechos de mayor significado social (huelga o libertad de sindicación, derecho al trabajo, etc) y, finalmente, recoge aquellos preceptos - en principio - de carácter exclusivamente programático, bajo la adecuada denominación de "Principios rectores de política social y económica". En suma, un planteamiento jurídico y una ordenación de los derechos que, al margen de lo que más adelante diré, responde a los criterios académicos de la doctrina sobre el tema en aquellos momentos.

En segundo lugar, esa condición dominantemente académica de los constituyentes propició así mismo un buen conocimiento del derecho comparado entonces vigente en los países de nuestro entorno en materia de derechos básicos de la persona, lo que con toda probabilidad también repercutió positivamente en el contenido final del Título I. Recordemos que para dichas fe- 
chas, lo que en lato sensu podríamos denominar como "constitucionalismo europeo ulterior a la II Guerra Mundial, se encontraba ampliamente experimentado en un conjunto de países que tenían un desarrollo económico y social relativamente parangonable con el nuestro; así mismo, la reciente transición política portuguesa posibilitó contar también con un texto constitucional de referencia, cercano en la distancia y próximo en el tiempo, que había ya intentado incorporar en materia de derechos las nuevas formulaciones que requería el nuevo contexto social y político de una sociedad occidental en el último tercio de siglo Xx. Y así, aunque no faltan en el Título I algunas formulaciones novedosas en cuanto no importadas (particularmente afortunada desde un punto de vista práctico me parece la determinación precisa de los derechos garantizados mediante recurso de amparo, así como -indirectamente- de aquellos otros que, sin necesidad de desarrollo legal, se hallan protegidos por la jurisdicción ordinaria), el constituyente aprovechó igualmente esas "experiencias" para incorporar elementos directamente tomados de otros ordenamientos que se habían revelado allí útiles. Para comenzar, por ejemplo, la constitucionalización misma de la noción de derechos fundamentales tomada de la Ley Fundamental de Bonn, para configurarlos como "derechos resistentes al legislador" y generadores de derechos subjetivos garantizados judicialmente; así mismo, tomada de la Constitución portuguesa es la cláusula de apertura al derecho internacional del art. 10.2, introducida como improvisado compromiso a una enmienda de UCD de finalidades muy distintas, y que, pese a tan azaroso procedimiento de incorporación al texto constitucional, tan buen juego ha dado a la hora de facilitar la incorporación del derecho comunitario de los derechos humanos a nuestro ordenamiento; o también, entre otras más, la constitucionalización explícita de la dignidad de la persona o el establecimiento entre nosotros de la garantía del "contenido esencial" categoría ciertamente abstrusa, pero que también ha contribuido a reforzar la operatividad de los derechos.

En tercer lugar, tampoco creo que sea ajeno a esta fuerte impronta académica de buena parte de los autores de la Constitución, el correcto empleo del lenguaje y del discurso jurídico y constitucional que luce en la declaración constitucional de derechos, lo que de una parte la ha permitido desplegar su operatividad tanto en el terreno ideológico (como expresión de un compromiso moral de los nuevos poderes públicos con los valores demoliberales), como en el terreno más inmediatamente jurídico (permitiéndola operar como norma generadora de auténticos derechos subjetivos inmediatamente aplicables por juzgados y tribunales) y de otra ha posibilitado su adaptación a contextos jurídicos y políticos muy diferentes.

En efecto, cuando la Constitución fue elaborada, así como en sus primeros años de vigencia, la declaración de derechos debía desempeñar una labor legitimadora del nuevo orden constitucional y del nuevo sistema institucional, alentando una cultura de los derechos en el funcionamiento de los poderes públicos en general y de los poderes ejecutivo (administraciones públicas) y judicial en particular. O dicho en otros términos, sin perjuicio de su obvia na- 
turaleza jurídica, el Título I había de cumplir primordialmente una función de clara significación política, cual es cambiar los hábitos del poder público y la percepción de éste por los ciudadanos. Y lo cierto es que la declaración de derechos con un lenguaje claro, atractivo y accesible para amplios sectores de la población, y con la inestimable colaboración del Tribunal Constitucional, fue capaz de generar esa cultura y propiciar una operatividad natural de los derechos fundamentales en la actividad jurídica cotidiana. Sin embargo, esta presencia cotidiana de la carta de derechos en la vida jurídica iba a abrir paso a una situación notablemente diferente. Los derechos fundamentales comenzaron a proyectarse sobre todas las áreas jurídicas del ordenamiento y a penetrar todo tipo de relaciones jurídicas (las relaciones entre particulares, también). De este modo los enunciados del Título I empezaron a ser percibidos no sólo como garantía de los derechos básicos de las personas o elemento de impulso o legitimación de determinadas políticas públicas, sino también como auténticos enunciados de derecho positivo que modulan las más heterogéneas relaciones jurídicas a través de sutiles elaboraciones doctrinales. La carta constitucional de derechos ya no será solo artillería de grueso calibre para garantizar los derechos consustanciales con la dignidad de la persona, sino depurada construcción jurídica presente en la vida jurídica de una realidad social y económica compleja. Y el contenido de la declaración constitucional de derechos del Título I, ahora ya con la ayuda de un sector más amplio, el estamento jurídico en general, también ha podido dar respuesta a este nuevo contexto y a estas nuevas exigencias.

El resultado, en mi opinión, es que el conjunto de preceptos que integran el Título I de la Constitución constituye una tabla de derechos que, como apuntaba al comienzo, merece globalmente una valoración positiva, tanto en cuanto al elenco de derechos proclamados y el modo de proclamarlos, como en lo que se refiere al sistema de garantías de los mismos. El Título I plasma un claro compromiso con los valores del Estado social y democrático de Derecho, pero paralelamente ese conjunto de preceptos se han revelado como unos enunciados constitucionales extraordinariamente operativos y de muy frecuente aplicación jurisdiccional, primero por la jurisdicción constitucional y más tarde, y de modo muy particular, por la jurisdicción ordinaria, lo cual reviste particular importancia porque, al margen del mayor o menor acierto que en puntuales ocasiones haya podido tener esta última aplicación judicial, es ésta la que ha posibilitado una mayor proyección de los derechos fundamentales en la vida jurídica y, en última instancia, una más auténtica eficacia cotidiana de los enunciados constitucionales permitiendo un muy satisfactorio nivel de vigencia de los derechos básicos del individuo en nuestro país.

Lo anterior no impide que, en términos doctrinales, quepa en todo caso formular algunos reparos al tratamiento constitucional de los derechos. Así es lugar común llamar la atención acerca de la ambigüedad con que en ocasiones se emplea la expresión misma de "derechos fundamentales". Ciertamente los textos constitucionales no están llamados a formular conceptos más o menos acabados de expresiones cargadas de connotaciones doctrinales (y la lo- 
cución "derechos fundamentales" lo está). Pero tampoco deben propiciar un cierto desconcierto doctrinal; por ejemplo con el empleo de dicha expresión en dos sentidos en principio notablemente distintos: es ya tópico en este punto señalar el muy diferente significado con que se emplea la expresión "derechos fundamentales" en el enunciado del Título I y en el encabezamiento de la Sección 1. ${ }^{a}$ del Capítulo II. Máxime si se tiene en cuenta que esta circunstancia, unida a la aparición de expresiones más o menos similares que se hallan desperdigadas en otros numerosos preceptos constitucionales (art. 13.1, encabezamiento del Cap. IV, arts. 54, 81, 86 o 149.1.1), introduce cierta dosis de imprecisión no exenta de consecuencias prácticas.

Asimismo, el proceso de elaboración del texto constitucional (el tan traído y llevado "Consenso") provocó algunas otras ambigüedades, solapando en un mismo precepto (y por ende en la regulación de un mismo derecho) posiciones ideológicas muy distintas (incluso antagónicas) poniendo al servicio de ello técnicas jurídicas igualmente diversas. De modo que en algún precepto el establecimiento de un derecho fundamental como derecho subjetivo va acompañado de un mandato al legislador o una garantía institucional, provocando innumerables problemas al ulterior interprete.

Con todo, creo que el aspecto peor resuelto por nuestro régimen constitucional de derechos fundamentales es, más allá del estricto ámbito del Titulo I, es el que deriva de las muy diversas reservas normativas que pesan sobre esta materia, que si bien tiene una evidente finalidad garantista, en verdad son fuente de una notable inseguridad en la materia. Recordemos brevemente. Por un lado está la reserva de ley que con carácter general proclama el art. 53 del texto constitucional y su conjugación tanto con el principio de legalidad que el propio texto proclama en alguno de sus preceptos como con las reservas de ley específicas que se establecen en la concreta regulación de algunos otros derechos. Y a esta difícil articulación, añádase la reserva de ley orgánica del art. 81 (categoría normativa que después de casi 30 años de vigencia del texto constitucional todavía no tiene perfiles definitivos), las prohibiciones que en esta materia pesan sobre el decreto ley y sobre el decreto legislativo y las obvias limitaciones que para esta cuestión obviamente tiene la ley autonómica. Limitaciones estas últimas que, sin embargo, no derivan de la naturaleza "fundamental" de los derechos a los que nos venimos refiriendo, sino de la reserva de ley orgánica o del ámbito material de competencias de las diversas Comunidades Autónomas. Una de las preguntas de esta encuesta que intentaré abordar más adelante no es ajena a esta última faceta.

Cuestión distinta es que, más allá de estos reparos al tratamiento constitucional de los derechos, observaciones por lo demás de carácter académicodoctrinal pero no muy relevantes para la presencia de los derechos básicos en la vida jurídica cotidiana, la Constitución, 30 años después de aprobada, se vea enfrentada en este punto a diversos retos, que eran impensables cuando fue elaborada.

No me alargaré en el desarrollo de este otro aspecto del tema planteado, pero si desearía a modo de botón de muestra dejar constancia de las debili- 
dades que, en mi opinión, actualmente ofrece el régimen jurídico de los derechos fundamentales de los extranjeros, dando lugar a los conocidos «bandazos" del régimen legal de la extranjería. O también, los problemas que plantea la convivencia en nuestro ordenamiento, junto con la declaración constitucional de derechos, de otras tablas de derechos, que ciertamente son expresión de un similar orden de valores pero cuyos concretos contenidos no siempre son coincidentes (me refiero obviamente a la Carta de Derechos la Carta de Derechos de la UE y el Convenio Europeo de Derechos Humanos) y que cada día gozan de mayor incidencia en nuestro sistema jurídico; máxime si se tiene en cuenta que cada uno de tales conjuntos normativos goza de su propio sistema jurisdiccional de garantía y cuya articulación ofrece también notables dificultades.

\section{LUIS MARÍA DÍEZ-PICAZO}

Mi opinión sobre la regulación que nuestra Constitución hace de los derechos fundamentales es globalmente positiva. Creo que es una de las partes mejor acabadas del texto constitucional, como lo demuestra que ha resistido muy bien — a diferencia de otras - el paso del tiempo.

\section{ÁNGEL GÓMEZ MONTORO}

Si nos atenemos a una valoración global, me parece que ésta ha de ser necesariamente positiva. Como tantas veces se ha puesto de relieve, se trata de un catálogo muy completo, que supo aprovechar la experiencia de las declaraciones internacionales de derechos y de las Constituciones más relevantes de nuestro entorno. Y pienso que el acierto del constituyente ha sido avalado por la realidad: la regulación constitucional ha permitido - y favorecido— la plena implantación y desarrollo de los derechos fundamentales en nuestro país.

También se ha puesto muchas veces de relieve, pero conviene recordarlo, el especial acierto que supuso la incorporación del art. 10.2 CE: una norma de apertura al Derecho internacional de los derechos fundamentales que tanto juego ha dado a la hora de buscar criterios interpretativos para determinar el contenido de los derechos o precisar sus límites.

Y por señalar alguna deficiencia, creo que el constituyente podía haber regulado mejor algunos temas relativos a la titularidad de los derechos fundamentales. La acertada decisión de dedicar un artículo - el 13- a regular los derechos de los extranjeros se vio frustrada por una regulación confusa que ha dado lugar a importantes polémicas tanto doctrinales como políticas bien conocidas por todos. Y siempre me he preguntado por qué el constituyente no incluyó ningún precepto relativo a la titularidad de derechos por las personas jurídicas; en concreto, me ha llamado la atención que inspirándose en el apartado II del art. 19 de la Ley Fundamental de Bonn en relación con el 
contenido esencial de los derechos (art. 53.2) y en el apartado IV del mismo artículo respecto de la tutela judicial de los derechos (nuestro art. 24.1), sin embargo ignorara el apartado III del precepto alemán, dedicado a los derechos de las personas jurídicas.

\section{GREGORIO PECES-BARBA MARTÍNEZ}

Creo que el título I de la CE es probablemente uno de los más avanzados y progresistas de los textos democráticos actuales. Se debe llamar la atención sobre la inclusión entre los derechos con mayor garantía y protección del derecho a la educación. Lo que supone una modificación sustancial del sistema clásico.

\section{JUAN JOSÉ SOLOZÁBAL ECHAVARRÍA}

\section{Toma de posición general}

Conviene partir quizás de una constatación, que me parece indudable, y que sin duda servirá de condicionante a lo que respecto a esta materia de derechos fundamentales pueda decirse, y es el desarrollo extraordinario que tanto en el nivel jurisprudencial como en el de la propia efectividad, se piense en el nivel normativo o su efectiva protección, conocen en España los derechos y libertades. Sin duda la descentralización territorial, y aun la propia organización institucional, como son delineadas en la Constitución, a pesar de presentar un balance extraordinariamente positivo, suscitan objeciones que son de nimia importancia en el caso de los derechos y libertades, donde la situación española es por muchos conceptos objeto de una valoración sin reservas.

Quiero decir que esto a mi juicio es atribuible a lo que podríamos llamar orden constitucional y no sólo a la Constitución misma, pero conviene tener en cuenta que si la regulación constitucional ha posibilitado la vigencia efectiva de los derechos y libertades de manera plena, ello ha acontecido a pesar de todas las consideraciones que desde una perspectiva dogmática pudieran hacerse. Quiere decirse entonces que sólo con mucha cautela y desconfianza deben formularse alternativas al tratamiento constitucional de la materia, que ha posibilitado que los derechos sean algo más que cláusulas prescriptivas, operantes en el plano del deber ser jurídico, para convertirse en verdaderas instituciones o realidades efectivas, se piense en la esfera de las facultades individuales o en el plano de la vida democrática y social.

\section{Derechos y Tribunal Constitucional}

Para la fundación de un verdadero orden constitucional de derechos y libertades fue capital la decisión tomada por los constituyentes en relación con 
la formulación explícita de una Declaración de derechos, que habría de gozar, por tanto, de una legitimidad directa y expresa del pueblo español, asumiendo un elenco extenso de derechos y libertades, y no contentándose con una legitimación indirecta, conseguida mediante una remisión a las declaraciones internacionales suscritas por España. Ello especialmente produciría una jurisprudencia definitoria del Tribunal Constitucional, sobre la base de la formulación concreta llevada a cabo por el constituyente. Sencillamente no es posible imaginarse la caracterización de los derechos en España, sin la labor extraordinaria del Tribunal Constitucional, bien interviniendo en procesos de inconstitucionalidad o, sobre todo, resolviendo recursos de amparo.

La virtualidad de la Declaración de derechos constitucional, por su parte, ha dependido de una postura que el Tribunal toma desde su mismo comienzo, afirmando la vinculación inmediata como derecho directamente aplicable de los derechos fundamentales, al menos en su significado obvio y fundamental, y sin esperar a su desarrollo legislativo. Cierto que el artículo 53 de la Constitución establece el carácter vinculante para los poderes públicos de los derechos fundamentales y cierto que la condición normativa de la Constitución se refiere a todo su contenido, por tanto también el concerniente a sus cláusulas prescriptivas, pero la vigencia de los derechos fundamentales, más allá de su fuerza derogatoria para el derecho preconstitucional, podría haber admitido su condicionamiento, eso sí constitucional, de la regulación legislativa, pues en suma al final todos los derechos, incluso los de libertad, lo son de configuración legal. Con mejor criterio y estableciendo una doctrina que después ha tenido su extensión en otros campos como el del derecho autonómico (me refiero en concreto a la de la idea material de bases, a deducir del derecho estatal no específico, de manera que no se imponga la obstaculización del despliegue del "desarrollo" normativo, por no existir la condición del soporte estatal que lo hiciese posible), el Tribunal constitucional ha autorizado la aplicación de aquellas facultades que gozan exclusivamente del reconocimiento constitucional sin haber sido objeto, todavía, de desarrollo legal (STC 75/1982 y 39/1983).

\section{SISTEMÁTICA DEL TÍTULO I DE LA CONSTITUCIÓN}

2. ${ }^{a}$ Más en concreto, ¿que juicio le merece la sistemática del Título I CE?. Si considerásemos como bipótesis de trabajo que boy se abriese un proceso constituyente ¿Vd. recomendaria seguir otros criterios clasificatorios de los diversos derechos fundamentales?

\section{LUIS AGUIAR DE LUQUE}

La Constitución española tiene clara vocación de integrarse al ordenamiento jurídico-positivo como bien acredita el enunciado del art. 9.1. Y par- 
tiendo de dicha premisa, la sistematización que realiza el Título I de los derechos que consagra me parece adecuada por cuanto toma como criterio de clasificación un elemento de indudable significado desde el punto de vista del derecho positivo: el diferente grado de fuerza vinculante y eficacia de los distintos derechos que allí se proclaman. Consecuentemente en el primer nivel se sitúan aquellos derechos que se hallan garantizados por el Tribunal Constitucional mediante el recurso de amparo, así como por la jurisdicción ordinaria a través de "un procedimiento basado en los principios de preferencia y sumariedad" y su eventual reforma requiere el procedimiento agravado de reforma constitucional. El segundo escalón lo integran aquellos que, al igual que los del primer apartado, "vinculan a todos los poderes públicos" y cuya protección se encomienda a los Tribunales ordinarios a través de los diversos procedimientos previstos por el ordenamiento. Y el tercer grupo lo forman aquellos "derechos", correctamente denominados "Principios" (esto es, mandatos de optimización en el terminología de R. Alexy), que, según expresamente señala el art. 53.3 informan "la legislación positiva, la práctica judicial y la actuación de los poderes públicos" pero que solo podrán ser alegados ante la jurisdicción ordinaria previo desarrollo legal.

Obviamente una clasificación de ese tipo no es sin embargo enteramente satisfactoria desde perspectivas doctrinales, que habitualmente operan con criterios de más enjundia jurídica y de mayor entidad teórica. A fin de cuentas la opción por conferir un determinado grado de eficacia y protección a un derecho (y, consiguientemente, incluirlo en un grupo u otro de los diferentes apartados en que se estructura el Título I) es fruto de una decisión del constituyente tomada a partir de criterios ideológicos y adoptada atendiendo al estadio de desarrollo social y económico del respectivo sistema estatal, pero carece de otras virtualidades a efectos de avanzar en la explicación de la naturaleza y contenido del derecho implicado.

El resultado es que la clasificación de los derechos que realiza el Título I contemplada con ojos académicos ofrece notables debilidades, cualquiera que sea el criterio doctrinal de sistematización que se adopte (como es obvio, en el terreno doctrinal se han hecho numerosísimas clasificaciones sobre la base de muy variados y heterogéneos criterios), en cuanto agrupa derechos de muy diferente naturaleza que protegen intereses individuales de muy distinto significado y cuya operatividad se despliega sobre la base de lógicas muy diferentes. $\mathrm{Y}$, a mayor abundamiento, los rótulos que encabezan las distintas Secciones, Capítulos o el propio enunciado del Título emplean expresiones de clara significación doctrinal pero que no siempre se emplean adecuadamente $\mathrm{y}$, menos aun, coherentemente; a la ambigüedad e imprecisión con que se emplea la expresión "derechos fundamentales" a la que más atrás hacía referencia, habría igualmente que añadir la de "deberes fundamentales", la de "derechos y libertades", o las de "libertades públicas" O "derechos y deberes de los ciudadanos"

Sin embargo, salvada estas últimas imprecisiones terminológicas del encabezamiento de los distintos apartados y aceptada la lógica de la sistematización que adoptara el constituyente que toma como eje el elemento deter- 
minante desde la óptica del derecho positivo, mi valoración de la sistematización de los derechos que realiza el Título I de la Constitución es positiva.

\section{LUIS MARÍA DÍEZ-PICAZO}

La sistemática del Título I me parece correcta. El criterio básico es el del régimen jurídico: derechos de la sección $1 .^{\mathrm{a}}$, derechos de la sección $2 .^{\mathrm{a}}$, y principios rectores de la política social y económica. Este criterio es bueno, porque es útil. Así lo demuestra que, de alguna manera, ha sido luego seguido por la Carta de Derechos Fundamentales de la Unión Europea. Si hubiera que abrir un nuevo proceso constituyente, no recomendaría un criterio distinto.

Dicho esto, hay algunas observaciones moderadamente críticas que podrían hacerse. La primera es que un catálogo de derechos no es el lugar más idóneo para los preceptos constitucionales relativos a nacionalidad y extranjería (arts. 11 y 12). Tampoco lo es, a pesar de las apariencias, para la previsión constitucional del Defensor del Pueblo (art. 54), que es una institución cuyo cometido es de fiscalización de la Administración, estén en juego o no los derechos fundamentales.

Otra crítica que yo haría es que hay un exceso clasificatorio: comprendo que la Constitución distinga entre derechos y principios rectores; pero sinceramente no encuentro ninguna buena razón para distinguir entre sección 1. ${ }^{a}$ y sección 2. ${ }^{\mathrm{a}}$. Creo que todos los derechos fundamentales deberían tener el mismo régimen jurídico e idénticas vías de protección. Cosa distinta, por supuesto, es el juicio que pueda hacerse del recurso de amparo, que no es el tema que nos ocupa ahora. Y cosa distinta es también que la Constitución prevea la figura de las leyes orgánicas, que creo deberíamos repensar, pues tenemos un sistema de fuentes innecesariamente barroco y una democracia demasiado proclive a las mayorías reforzadas; y ni lo uno ni lo otro me parece demasiado bueno. Profundizando algo más, la verdad es que la única razón que podría esgrimirse para defender la distinción entre la sección 1 . $^{\mathrm{a}}$ y la sección 2. ${ }^{a}$ tendría que ver con la reforma constitucional: sólo algunos derechos fundamentales merecen ser considerados como núcleo central del régimen constitucional. Pero, aun así, la objeción subsiste: no todo lo que está en la sección $1 .^{\mathrm{a}}$ es tan importante y algunas cosas de la sección $2 .^{\mathrm{a}}$, en cambio, sí lo son. Pienso en el matrimonio y en la propiedad. Y además, es cuestionable que deba haber una dualidad de procedimientos de reforma constitucional: la experiencia enseña que uno de los más graves defectos de nuestra Constitución es su excesiva rigidez.

\section{ÁNGEL GÓMEZ MONTORO}

Es evidente que desde el punto de vista taxonómico nuestra Constitución no ha sido especialmente cuidadosa al sistematizar los derechos del Título I. 
Creo, sin embargo, que esto tiene una importancia relativa pues lo relevante no son tanto los criterios de clasificación como la eficacia normativa y las garantías de los derechos y, en este sentido, nuestra Constitución es lo suficientemente clara y sistemática.

Es verdad que la declaración de derechos podría ganar en claridad expositiva si se siguiera, por ejemplo, un esquema similar al de la Carta Europea (dignidad, libertades, igualdad, solidaridad, ciudadanía, justicia). Creo, sin embargo, que es preferible la opción de nuestro constituyente de agrupar los derechos en función de las garantías normativas (procedimiento de reforma constitucional, resera a ley orgánica, etc.) y judiciales (recurso de amparo, procedimiento judicial preferente y sumario, etc.). Por ello, en un hipotético proceso constituyente no sería partidario de revisar la sistemática general, aunque sí sería favorable a la introducción de algunas reformas. En concreto, comparto la opinión de que el derecho de propiedad debería pasar a la sección primera al objeto de que pudieran llegar previamente al Tribunal Constitucional asuntos que tienen abierta al vía del Tribunal de Estrasburgo. Y sería partidario de una revisión más a fondo del Capítulo III del que, posiblemente, habría que quitar algunas cosas y ordenar mejor sus contenidos.

\section{GREGORIO PECES-BARBA MARTÍNEZ}

No es decisiva la denominación de los capítulos y de las secciones. Lo significativo son las tres dimensiones de los contenidos donde se agrupan y que me parece adecuada. En la primera, los derechos con especial protección del recurso de amparo, y por consiguiente, aquellos de mayor relevancia; En la segunda, aquellos que son igualmente derechos, pero que carecen de esa protección especial del recurso de amparo y que tienen que protegerse por otras vías jurídicas ordinarias; y finalmente, los principios rectores, que son una solución adecuada para situaciones más complejas y problemáticas, puesto que se exige un desarrollo legal para que sean susceptibles de titularidad individual y puedan ser objeto de una pretensión judicial. Sin embargo, sí que son obligatorios para los poderes públicos, que no podrán actuar en ningún caso con producciones normativas contrarias a los principios rectores.

\section{JUAN JOSÉ SOLOZÁBAL ECHAVARRÍA}

\section{La explicitacion de los criterios materiales de fundamentalidad}

Mi sustancial conformidad con la actuación protectora e interpretativa de los derechos fundamentales llevada a cabo, como he señalado, en términos sustancialmente correctos, y la normalidad con que se han impuesto sin apenas contestación me llevan, como decía al principio, a abstenerme de hacer sugerencias modificativas del Título I de nuestra Constitución. Así, aunque 
fuese deseable, no considero necesario explicitar la razón constitucional de la fundamentalidad, que sin duda es la vinculación de los derechos con la dignidad de la persona, de la que constituyen la proyección positiva, pero que tiene que ver asimismo con las vías, esencialmente jurisdiccionales, de protección de los bienes jurídicos a que se refieren los derechos, necesariamente por tanto vinculados a la condición del Estado como forma jurídica y política antes que con su condición social, por mas que, con toda corrección, muchos consideremos que la dignidad de la persona y sus oportunidades de desarrollo requieren de determinadas prestaciones, que por tanto no pueden ser consideradas como contenidos programáticos u objetivos dependientes de la voluntad de los poderes públicos. Al respecto, como se hace en la declaración de Derechos del (frustado) Tratado tal vez debería pensarse en la necesidad de distinguir en nuestro Capítulo 3 del Título I entre normas directivas, aunque plenamente vinculantes como derecho que son, y derechos sociales, exigibles con el contenido constitucional previsto y según las posibilidades organizatorias de los diferentes servicios públicos, contenidos en dicho título. Piénsese en los derechos a la salud o al medio ambiente. Se trataría de meros derechos constitucionales, pero con un cierto ribete de fundamentalidad deducido de su relación con las exigencias de la dignidad, y cuyo entendimiento de este modo está favorecido por disponer de la estructura normativa que corresponde a las cláusulas que reconocen este tipo de figuras. Así puede pensarse en la diferencia estructural entre un derecho fundamental como la educación y el de la salud, si se prescinde de la condición espiritual de la educación, que tiene que ver más con la orientación del derecho que con el modo de garantizar su ejercicio, asegurado, como en el caso del derecho a la salud a través de prestaciones realizadas por un servicio público en cuanto a su cumplimiento. En todo caso, es cierto, son derechos reconocidos en términos legales (pero en la práctica todos los derechos son de configuración legal) con deficiente estructura constitucional, pues su desarrollo no requiere de ley orgánica, y, desde luego, sin protección jurisdiccional especial, a través del amparo.

\section{AMPLIACIÓN DEL CATÁLOGO DE DERECHOS}

3. 'Piensa que actualmente nuestra Constitución debería proclamar y garantizar otros derechos fundamentales y, en su caso, cuales serían estos?

\section{LUIS AGUIAR DE LUQUE}

Comenzaré con una acotación. Cuando el cuestionario facilitado emplea aquí la expresión derechos fundamentales, quiero entender que se refiere a la acepción más restringida y formal de dicha expresión, esto es, los derechos proclamados en los arts. 14 a 29 de la Constitución. El alto grado de formali- 
zación y garantías que rodea a esta categoría así entendida, es la que permitiría lamentar hipotéticas ausencias de "otros" derechos en dicho catálogo.

Pues bien, sentado este punto de partida y dejando al margen las dificultades con que podría tropezar una propuesta de ese tipo dada la extremada rigidez que rodea a ese conjunto de preceptos, esto es, situado en el exclusivo terreno de la especulación jurídica, no considero necesario, ni tan siquiera conveniente, ampliar el elenco de derechos fundamentales que allí se proclaman. Varias circunstancias concurren para mantener dicha opinión.

De una parte, aunque han trascurrido ya casi treinta años desde que la Constitución fue elaborada y evidentemente se han producido muchos y muy importantes cambios en campos muy variados (así en al ámbito social, económico, cultural, tecnológico...) no me parece que se puedan detectar lagunas y deficiencias significativas en el elenco derechos consagrados por nuestro texto constitucional. Y menos aun que esas nuevas concreciones de la libertad y dignidad que pudieran materializarse como nuevos derechos fundamentales, sean ampliamente compartidos por la ciudadanía. Basta para confirmar lo dicho comparar la tabla de derechos del Título I de la Constitución con la relación de derechos que consagra la Carta de Derechos Fundamentales de la Unión Europea; con las lógicas diferencias de redacción, que obviamente no son irrelevantes porque en ocasiones determinan diferencias de contenido pero que no afectan al tema ahora objeto de consideración, son muy puntuales las innovaciones que, en cuanto auténticos nuevos derechos, podrían detectarse en la Carta europea y que no estén comprendidos en el catálogo de nuestra Carta Magna.

De otra parte, como ha quedado apuntado precedentemente, en mi opinión uno de los mayores méritos de nuestra declaración de derechos es la explícita identificación de los derechos que gozan de mayor fuerza vinculante, eficacia jurídica y protección constitucional, dotando a la categoría "derechos fundamentales" de un extremado (y en mi opinión positivo) formalismo. Una eventual y generosa ampliación del catálogo de derechos reconocidos correría el riesgo de desvalorizar el significado y alcance de los que actualmente aparecen recogidos.

Finalmente dada la adaptabilidad de que han dado prueba los enunciados de la Constitución que consagran derechos, a la que más atrás he hecho referencia, así como la integración de nuestro ordenamiento en un espacio jurídico en el que la interpretación del régimen de los derechos fundamentales se retroalimenta recíprocamente en sus diferentes niveles, no me parece necesaria una hipotética incorporación de nuevos derechos al texto constitucional. Piénsese, por ejemplo, en los denominados como derechos de nueva generación (sea esta tercera o cuarta), a los que recientemente el Presidente del Tribunal Supremo ha dedicado el Discurso de apertura del año judicial (septiembre de 2007). Bien puede afirmarse que todos los derechos allí explícitamente recogidos como integrantes de tal categoría (derecho a una buena administración, al medio ambiente, a la autodeterminación informativa y a la protección de datos y al derecho al consentimiento informado y a la auto- 
nomía del paciente) se hallan ya en buena medida comprendidos en el capítulo de derechos fundamentales de nuestro texto constitucional.

\section{LUIS MARÍA DÍEZ-PICAZO}

No creo que la Constitución española, que es relativamente reciente en términos históricos, tenga serias carencias en materia de derechos. La comparación con el Convenio Europeo de Derechos Humanos, que es la referencia obligada en este campo, así lo demuestra. Es cierto que, desde la aprobación de la Constitución, han tenido lugar dos importantísimos cambios: la penetración de los ordenadores en todos los aspectos de la vida, y el espectacular desarrollo de los conocimientos de genética. Ambos cambios tienen, como es obvio, implicaciones en materia de derechos fundamentales. Pero es dudoso que sea necesario añadir algo a lo que ya disponen los arts. 15 y 18. Pienso que los problemas de derechos fundamentales que surgen en esos dos terrenos no se resolverían mejor con algún nuevo precepto constitucional, que por fuerza sería breve y lapidario. La jurisprudencia constitucional y europea, eventualmente con apoyo en tratados internacionales especializados, debería ser suficiente para hacer frente a esos nuevos problemas.

Aún con respecto a si sería conveniente declarar más derechos, conviene hacer otra reflexión: en mi opinión, no es buena la tendencia a multiplicar los derechos fundamentales, ni a engordar el contenido de los ya existentes. Y no lo es por dos motivos. En primer lugar, porque la inflación de derechos conduce a la devaluación de los derechos. Para que los derechos fundamentales sean verdaderamente útiles —es decir, "triunfos" frente a la voluntad de la mayoría, en el sentido de Dworkin-, es necesario que no sean numerosos. Si se intenta usar un arma tan poderosa todos los días, el arma pierde efectividad. En segundo lugar, no hay que olvidar que la lógica de los derechos fundamentales es, por usar de nuevo una expresión de origen norteamericano, una lógica "Contra-mayoritaria". Esto quiere decir que los derechos fundamentales sirven para limitar la decisión por mayorías y, para un demócrata, ello sólo puede estar justificado en unos pocos supuestos: cuando se trata de salvaguardar bienes o valores que deben quedar a reparo de la voluntad de la mayoría.

\section{ÁNGEL GÓMEZ MONTORO}

Como regla general me parece que hay que ser prudente a la hora de incluir nuevos derechos fundamentales y ello por el riesgo de desnaturalizar esta categoría, bien precisa y de tanta trascendencia, si se incluyen contenidos que difícilmente pueden ser reconducidos a la estructura y a las garantías propias de estos derechos

Dicho esto, sí sería partidario de incluir expresamente en la Constitución algunos derechos que no aparecen como tales en el texto constitucional y 
cuya formulación ha sido obra de la jurisprudencia constitucional. Estoy pensando en el derecho a la protección de datos de carácter personal, deducido del art. 18.4 CE que, en realidad, no contiene sino un mandato al legislador. Pienso también en el derecho a no ser condenado dos veces por los mismos hechos (ne bis in idem), que el Tribunal ubica - con un apoyo literal endeble- en el art. 25.1 CE. Cabría asimismo la posibilidad de positivar los derechos que el Tribunal Constitucional viene deduciendo del art. 24.1 CE: acceso a la jurisdicción y a los recursos legalmente establecidos, a una resolución judicial motivada y congruente a la ejecución de las resoluciones judiciales...

Aunque no se trate de crear nuevos derechos, considero necesario completar la regulación de algunos de los ya existentes para dar respuesta a algunas de las cuestiones más acuciantes de nuestro tiempo. Estoy pensando en concreto en la defensa de la vida y la integridad física y moral frente a las nuevas posibilidades que presenta la ciencia tal y como se ha hecho, por ejemplo, el art. II-63 de la Constitución Europea.

Por las razones antes apuntadas y sobre las que volveré en la siguiente pregunta, encuentro más problemas para incluir como verdaderos derechos fundamentales algunos contenidos del Capítulo III del Título I de la Constitución. Estoy pensando, por citar algunos casos, en la tutela del medio ambiente, el derecho a la salud o a una vivienda digna.

\section{GREGORIO PECES-BARBA MARTÍNEZ}

Creo que deberían quizás ampliarse los llamados nuevos derechos y situarlos en un ámbito mayor de protección de la que tienen actualmente. Me refiero al medioambiente, los derechos de grupos específicos, como enfermos, consumidores, presos, etc. También puede ser un cauce de ampliación el desarrollo del artículo 9.2. en lo que se refiere a la promoción de la libertad y de la igualdad y a la remoción de los obstáculos que se opongan a ellas.

\section{JUAN JOSÉ SOLOZÁBAL ECHAVARRÍA}

\section{Incompletud constitucional: Jurisprudencia y legislación sobre derechos}

La dependencia jurisprudencial de los derechos fundamentales viene especialmente causada por la propia condición de los mismos, incluidos en cláusulas de estructura principialista, sin desdeñar las oportunidades para la clarificación de los derechos que se deducen en su aplicación concreta como verdadera law in action, especialmente en confrontación con las exigencias derivadas de otros derechos y bienes constitucionales en conflictos o colisiones concretas y que pueden llegar al Tribunal especialmente por la vía del amparo y la cuestión de inconstitucionalidad. El caso es que la incompletud de las cláusulas prescriptivas da origen a una importante actuación de confi- 
guración y protección por parte del legislador y de determinación por parte del Tribunal Constitucional. La actuación normativa se produce a través del desarrollo que lleva a cabo la ley orgánica, en una actuación definidora y especificadora en relación con las facultades y pretensiones que el derecho necesariamente comprende y de la regulación a través de la ley ordinaria o estatal, a mi juicio siempre con un significado secundario y con un propósito organizador y tuitivo, antes que configurador y organizativo. La cuestión es separar la actuación necesaria del legislador, y cuyos perfiles someramente recordados aquí ha dejado bien claros la jurisprudencia del Tribunal Constitucional, y la que lleva a cabo el supremo intérprete constitucional. Diríamos que la actuación del legislador es la ordinaria y es la que incluye una motivación política en su caso, cuestión esta delicada pues implica dar una respuesta positiva a la pregunta acerca de la existencia de una política de derechos fundamentales. Ciertamente admitir una ordenación legislativa de los derechos no supone ignorar que no todos los derechos lo son de configuración legal, aunque sí reconocer la necesidad de una regulación que especifique las facultades o pretensiones en que los derechos consisten.

Temporalmente, en cambio, la actuación del Tribunal Constitucional se produce tras la intervención del legislador, disponiendo sobre la misma. El Tribunal cuyos fallos se imponen sobre la ley, de manera que la superioridad en el sistema de fuentes de la sentencia sobre la ley, no ofrece dudas, tiene no obstante condicionada su actuación desde una doble perspectiva, pues la sentencia constitucional, en primer lugar, por exigencias del principio de congruencia no puede ni ampliar su control del solicitado ni, mucho menos, ejercerlo sin que quienes lo hayan demandado cuenten con la legitimación procesal correspondiente. Además, en segundo lugar, los criterios del Tribunal pronunciándose sobre la constitucionalidad de una ley o de una actuación concreta de un poder público, cuestionada a su vez ésta en razón de su lesión autónoma o derivada de la norma que le cubriese legalmente, han de ser exclusivamente técnico juridicos, no dando opción a consideración alguna de tipo político, lo que veíamos no ocurría con la ley.

Con todo afirmar la superioridad definitoria del Tribunal sobre la ley no responde a nuestra pregunta sobre los términos de la intervención en tal materia del Tribunal, colmando o reduciendo la incompletud e indeterminación constitucional. Este problema sólo se puede resolver recordando la condición del Tribunal como órgano o poder constituido que está también sometido a la Constitución, aunque esta sea lo que aquel como supremo intérprete diga. No es un poder constituyente constituido con capacidad de cambiar la Constitución, directamente o inconstitucionalmente a través de una mutación constitucional. Cierto es un intérprete dinámico de la misma, pero de modo que la adaptación no lleve al cambio de la Constitución. Importante es al respecto que no dificultemos su actuación conservadora de la Constitución, insistiendo en el procesalismo de esta o la levedad de contenido, olvidando la distancia entre la Constitución y otro tipo de normas cuya observancia corresponde garantizar al Tribunal Constitucional. 
Por tanto el Tribunal no puede crear nuevos derechos, lo que por las razones que sabemos está vedado a quien no sea el constituyente. La actuación constituyente supone una decisión incondicionada sobre la planta institucional que se da una comunidad política y los derechos de sus ciudadanos. Por eso no hay otros derechos fundamentales que los establecidos en la Constitución, y los que figuran en la misma lo hacen de modo constitutivo, no a título ejemplificativo. Lo que hace el Tribunal con los derechos siempre es muy importante pero tiene un valor consolidador, certificando la corrección de la actuación del legislador o la aportación de la jurisprudencia internacional en relación con la determinación del contenido necesario, no obligatoriamente esencial, de los derechos. El Tribunal pude llamar la atención sobre la conexión sistemática de algunos derechos, también puede proceder a una redenominación de los mismos. $\mathrm{O}$ a atribuirles un contenido que puede establecerse de modo un tanto inconvencional o, al menos, desusado. Modélica en este sentido es la jurisprudencia del Tribunal Constitucional sobre los derechos contenidos en el artículo 27 CE. Así la Sentencia 86/1987 llama la atención sobre los diversos tipos de preceptos en dicha disposición, destacando que a pesar de la ubicación constitucional del mismo en él se contienen otro tipo de figuras que no son derechos, subrayándose asimismo la dimensión prestacional del derecho a la educación.

En la Sentencia 5/1981 por lo que toca a la conexión sistemática de los derechos fundamentales se afirma que la libertad de enseñanza ha de considerarse proyección de la libertad ideológica y religiosa (art.16CE) y el derecho a expresar libremente el pensamiento, ideas u opiniones (art. $20 \mathrm{CE}$ ).

En lo que se refiere a la determinación de los derechos incluidos en el precepto en cuestión se advierte que el derecho de dirección del centro privado está incluido en la libertad de enseñanza de los titulares del centro y su contenido esencial se determina positivamente como el derecho a mantener el carácter propio mediante las facultades de propuesta de estatutos, así como las de nombrar y cesar a los órganos de dirección administrativa, pedagógica y del profesorado; y negativamente de modo que se excluyan limitaciones y restricciones que impidan de hecho dichas facultades decisorias esenciales. Esta sentencia no sólo señala las facultades a entender comprendidas en su seno sino que se les caracteriza doctrinalmente, así, para el Tribunal Constitucional, el derecho a crear centros docentes se trata de un derecho, aunque derivado, autónomo y no auxiliar de ningún otro - como el de los padres de que sus hijos reciban una educación acorde con sus convicciones- y no limitado a los aspectos religiosos o morales de la actividad educativa.

Las facultades cusitransformadoras del Tribunal Constitucional se muestran en el caso de la autonomía universitaria, que no debe ser considerado garantía institucional sino derecho fundamental, precisamente la dimensión institucional o colectiva de la libertad académica, nuevo nombre de la libertad de enseñanza cuya dimensión individual es la libertad de cátedra y consiste en aquellas facultades imprescindibles para asegurar un espacio de libertad intelectual en el que la Universidad cumpla con sus funciones de creación, mantenimiento y desarrollo de la ciencia, la técnica y la cultura (STC 187/1991). 


\section{PRINCIPIOS RECTORES DE LA POLÍTICA SOCIAL Y ECONÓMICA}

$4 .^{a}$ Abandonando el terreno de constitutione ferenda, ¿el alcance de los denominados principios rectores de la política social y económica debe atenerse a lo preceptuado en el art. 53.3 CE, tal y como lo interpreta nuestro Tribunal Constitucional? o ¿debería atribuirse a los mismos otros efectos?

\section{LUIS MARÍA DÍEZ-PICAZO}

Creo que los principios rectores de la política social y económica están bien como están. Se puede discutir si es oportuno que una constitución contenga objetivos sociales, que no son derechos exigibles ni normas directamente invocables. La gran objeción a este tipo de disposiciones esencialmente programáticas es que pueden resultar engañosas para los ciudadanos legos en derecho; y, si esto ocurre, merma la legitimidad de la propia constitución. Dicho de otra manera, no es bueno que haya promesas constitucionales - reales o imaginarias - incumplidas.

Ahora bien, una vez decidido que la constitución contenga objetivos sociales, es mejor hacerlo como lo ha hecho la Constitución española. Lo contrario - esto es, que esos objetivos sociales tengan plena fuerza normativa- conduce, antes o después, a un resultado inaceptable en términos de democracia y, aún antes, de buen funcionamiento del Estado: la imposibilidad de establecer prioridades presupuestarias y de gestionar razonablemente las finanzas públicas.

No es ocioso añadir que la falta de fuerza normativa directa de los principios rectores de la política económica y social no equivale a irrelevancia constitucional: se trata, en todo caso, de valores constitucionalmente proclamados, por lo que pueden y deben ser utilizados como instrumentos privilegiados en la interpretación constitucional y, en particular, en sede de ponderación.

\section{ÁNGEL GÓMEZ MONTORO}

Me parece que este es uno de los puntos de mayor interés en el momento presente porque se aprecia tanto en el plano político como en el de las decisiones judiciales una tendencia a dotar a esos principios de una eficacia que trasciende la prevista en el art. 53.3 CE. Me interesa en concreto referirme a los intentos de iusfundamentalizar algunos de esos principios como la tutela del medio ambiente o el derecho a la salud. Un claro ejemplo de este tipo de construcciones lo constituyen las sentencias de nuestro propio Tribunal Constitucional en relación con la tutela frente al ruido. En concreto, en las SSTC 119/2001 y 16/2004 el Tribunal admite que emisiones de ruido o incluso de olores especialmente intensas y perturbadoras pueden dañar los bienes protegidos por derechos tales como la integridad física y moral (art. $15 \mathrm{CE}$ ), la intimidad (art. 18.1 CE) o incluso la inviolabilidad del domicilio (art. 18.2 CE). 
Y algunas construcciones similares se han producido en relación con el derecho a la salud. Así, en la STC 220/2005 el Tribunal admite que "el derecho a la integridad física podría verse lesionado no sólo por acciones, sino también por omisiones de los poderes públicos - como podría ser el caso de una negativa injustificada a conceder una prórroga de baja por incapacidad laboralque deberían ser amparadas por los Tribunales si como consecuencia de aquéllas se produjera una lesión del derecho de modo real y efectivo".

No me cuesta entender las razones que están detrás de este tipo de decisiones judiciales. Junto a concretos problemas humanos muchas veces importantes, existe más que nunca la percepción de que la legitimidad de un Estado que se califica a sí mismo como Social depende cada vez más de la capacidad de garantizar un mínimo de calidad de vida (mínimo que, además, se va elevando de forma progresiva). Ahora bien, tengo serias dudas de que la manera más correcta de avanzar en estas importantes cuestiones sea a través de una interpretación expansiva del contenido de los derechos fundamentales que puede llevar no sólo a su desnaturalización sino, al mismo tiempo, a una alteración de las relaciones entre el poder político (y en particular el legislador) y los órganos jurisdiccionales. Cabe al menos preguntarse si no es más adecuado exigir al legislador que establezca las regulaciones necesarias para asegurar el respeto de las condiciones medioambientales adecuadas - lo que es perfectamente acorde con el entendimiento de los principios rectores del Capítulo III como mandatos al legislador - y reconocer a los ciudadanos una amplia legitimación procesal para exigir su cumplimiento siempre que, de una u otra manera, se vea afectado su ámbito de intereses.

Entiendo que este planteamiento es coherente con la obligación de proteger estos contenidos que se deduce de la jurisprudencia del Tribunal Europeo de Derechos Humanos. La condena a España en sentencias como López Ostra contra Reino de España (1994), obliga al Estado a prestar una tutela suficiente de determinados bienes de la persona pero es dudoso que imponga una interpretación expansiva del contenido de los derechos fundamentales. La correcta comprensión del tema pasa por no ignorar la posición del Tribunal de Estrasburgo: éste sólo puede garantizar ciertos bienes e intereses de las personas a través de la tutela de derechos, sin que pueda dejar de otorgar la protección que exige la Carta de Roma porque el Estado alegue el cumplimiento de la legislación interna o incluso la ausencia de ésta. Pero dicha tutela puede realizarse en el ordenamiento interno de formas distintas y creo que una legislación suficientemente protectora unida a la existencia de acciones judiciales para asegurar su cumplimiento haría innecesaria la invocación directa de la Constitución y más en concreto de sus derechos fundamentales. Hace falta, eso sí, la suficiente sensibilidad del legislador para dar respuesta pronta y eficaz a estos problemas, pues no pocas veces las construcciones jurisprudenciales que podríamos calificar como audaces son la respuesta frente a la pasividad del poder público y, más específicamente del legislador, o al menos ante la tardanza en dar una solución adecuada a problemas nuevos y muchas veces acuciantes (como puso de relieve, por ejemplo, el supuesto resuelto por la citada STC 16/2004). 


\section{GREGORIO PECES-BARBA MARTÍNEZ}

Creo que es correcta la doctrina del Tribunal Constitucional.

\section{JUAN JOSÉ SOLOZÁBAL ECHAVARRÍA}

Contestada en la pregunta núm. 2.

\section{ESTATUTOS DE AUTONOMÍA Y DERECHOS}

5. ¿Puede sintetizarnos su criterio sobre el paso que dan nuevos Estatutos de Autonomía de incluir proclamaciones propias de derechos fundamentales?

\section{LUIS AGUIAR DE LUQUE}

La reciente incorporación a varios de los nuevos (o remodelados) Estatutos de Autonomía de diversos preceptos que sedicentemente consagran una serie de derechos básicos para el ciudadano, en ocasiones hasta configurar formalmente una tabla estatutaria de derechos (eludo la expresión derechos fundamentales porque ni los Estatutos emplean dicha denominación, ni en puridad creo que puedan calificarse de tales) ha suscitado una amplia polémica doctrinal (Ferreres, Biglino, Carrillo, Díez Picazo o Caamaño han sido algunos de los más explícitamente implicados). Y más allá de ello, tanto en "corrillos" académicos, como en los medios de comunicación en general, la presencia de este tipo de preceptos en los Estatutos de Autonomía ha suscitado numerosos comentarios, las más de las veces manifestando recelos y reservas. Resulta pues difícil decir algo novedoso sobre esta cuestión. Optaré, por tanto, más modestamente por intentar sistematizar los principales problemas y dudas que a título personal me suscitan estos enunciados.

Situado en ese terreno el primer interrogante que este tema plantea es si unas disposiciones estatutarias de ese tenor pueden ser compatibles con el mandato de igualdad que en sentido material consagra el artículo 139.1 de la Constitución y que en el plano competencial se colige del contenido del artículo 149.1.1.

Sin embargo, más allá de las conclusiones a las que pudiera llegarse desde una interpretación excesivamente literalista de uno y otro precepto, no creo que tales artículos del Título VIII de la Constitución supongan un obstáculo serio para los preceptos estatutarios declarativos de derechos, como bien han apuntado la práctica totalidad de autores que han analizado esta cuestión.

De una parte porque el artículo 139.1 se limita a proclamar un mandato de igualdad en el interior de cada uno de los subordenamientos autonómicos, pero no en la relación de unos con otros. Como plásticamente sugiriera en su 
día el malogrado Ignacio de Otto, para la correcta interpretación de este precepto constitucional basta con realizar una relectura del mismo en el orden gramatical adecuado, esto es, "en cualquier parte del territorio del Estado, todos los españoles tienen los mismos derechos y obligaciones", que en absoluto implica que los españoles tengan necesariamente los mismos derechos en cualquier parte del territorio; por lo demás la vieja sentencia del Tribunal Constitucional "Sobre centros de carga y descarga" (STC 37/81) ya esclareció esta cuestión.

Y por lo que se refiere al enunciado del artículo 149.1.1, difícilmente puede entenderse contrariado su contenido por aquellas disposiciones estatutarias que consagran derechos, toda vez que en nada se ve afectada la competencia estatal para regular las condiciones básicas que garanticen la igualdad de todos los españoles en el ejercicio de sus derechos constitucionales, máxime si como ha sucedido en todos los Estatutos reformados hasta la fecha, explícitamente se excluye que tales contenidos estatutarios pueden alterar el régimen de distribución de competencias o el alcance de los derechos fundamentales consagrados en la Constitución (por todos, art. 37.4 del nuevo Estatuto de Cataluña).

Un segundo interrogante que suscitan las cláusulas declarativas de derechos, éste ya de mayor envergadura, es el de si los Estatutos de Autonomía, que como es sabido constituyen una categoría normativa específica y singular de nuestro ordenamiento, están habilitados para acoger enunciados de este tipo.

Pues bien, a la hora de abordar dicha cuestión lo primero que hay que dejar nítidamente sentado, como mayoritariamente han constatado los autores que se han ocupado de esta cuestión, es que los Estatutos de Autonomía no son parangonables con las constituciones de los Estados miembros de una Federación. ${ }^{(i)} \mathrm{Ni}$ por su procedimiento de elaboración o reforma, que en el caso español exige la intervención del poder legislativo del Estado, (ii) ni por su función constitucional, que en el caso de los Estatutos de Autonomía va más allá de la mera organización institucional para ocuparse de la determinación de las competencias de la respectiva Comunidad Autónoma y, con ello, entrar de lleno en la distribución de competencias entre el Estado y las Comunidades Autónomas, cuestión ésta que en los Estados Federales viene fijada por la Constitución, ${ }^{(i i i)}$ ni por el órgano encargado de velar por la supremacía de los Estatutos de Autonomía en el seno del ordenamiento, que en el sistema español corresponde al Tribunal Constitucional, las constituciones estatales de los sistemas federales pueden servir para explicar estos nuevos contenidos de los Estatutos de Autonomía (véase V. Ferreres, de quien tomo estas ideas). O dicho en otros términos, la justificación de estos preceptos estatutarios declarativos de derechos no puede buscarse en experiencias de otros ordenamientos, sino que el problema ha de resolverse exclusivamente en clave interna, esto es, tomando como única referencia los enunciados de nuestro texto constitucional. Y justo es reconocer, en favor de las tesis de los críticos de este tipo de preceptos, que el contenido del artículo 147.2 de la Constitución puede representar un cierto obstáculo por cuanto —en principio- dicho 
precepto constitucional no parece contemplar como contenido eventual de los Estatutos de Autonomía una declaración de derechos.

Por otra parte no se puede ignorar que los Estatutos de Autonomía son leyes orgánicas y, como leyes de mayoría cualificada, la determinación de su ámbito de reserva debe ser interpretado restrictivamente, sin que el elenco de materias reservadas quede a disposición del legislador. Así lo ha proclamado con carácter general y de modo reiterado el Tribunal Constitucional; por todas la sentencia 76/83 de 5 de agosto (caso LOAPA) cuando afirmó que "dada la congelación de rango que estas [reservas] suponen, la rigidez del ordenamiento no puede llevarse más allá de los supuestos específicamente tasados".

En todo caso, no creo que con lo que se acaba de señalar se avance mucho en el esclarecimiento del tema, salvo constatar la necesidad de efectuar una interpretación restrictiva de los contenidos del art. 147.2. Pues el problema sigue situado en los mismos términos que se expusieron más atrás, esto es, si la incorporación de cláusulas declarativas de derechos "cabe" en la reserva de contenidos estatutarios que efectúa el art. 147.2.

Y desde dicha perspectiva mi respuesta es positiva.

Básicamente porque entiendo que la interpretación del art. 147.2 no puede desconocer la naturaleza del Estatuto de Autonomía como materialización del autogobierno de la Comunidad Autónoma respectiva (el Estatuto de Autonomía no es una ley orgánica más, como bien acredita su procedimiento de elaboración y reforma que inexcusablemente precisa la intervención — sea directa, sea a través de representantes- de los destinatarios de la misma), ni se puede desvincular de la definición que de dicho tipo de norma ofrece el apdo. 1 de ese mismo art. 147: "norma institucional básica", esto es, norma creadora y conformadora de los elementos esenciales de una estructura organizativa específica, singular y dotada de amplios niveles de autogobierno como es una Comunidad Autónoma.

En mi opinión, solo una lectura excesivamente rígida y encastillada en una determinada concepción de las normas generadoras de derechos individuales, puede negar a los Estatutos de Autonomía la capacidad de incorporar a su texto, junto a los contenidos explícita y literalmente recogidos en el art. 147.2, otros preceptos que contengan principios, esto es, legitimadores de futuras líneas de acción de los poderes públicos o reglas eventualmente generadoras de derechos subjetivos, lo que, hasta cierto punto, es una consecuencia obligada de su condición de norma institutiva de la Comunidad. Baste recordar al respecto que los Estatutos de Autonomía que podríamos denominar de primera generación, ya contenían algunos enunciados de este tipo (así, el Estatuto de Cataluña de 1979 en el art. 6 alude a los "derechos políticos" de los catalanes, algo que hay que interpretar en conexión -entre otros- con el art. 31 que proclama que el Parlamento de Cataluña será elegido "por sufragio universal, libre, directo y secreto", y el art. 8, amén de concretizar la titularidad de los derechos fundamentales por los catalanes, encomienda a la Generalidad las tareas que el art. 9.2 de la Constitución atribuye con carácter general a los poderes públicos: "promover las condiciones para 
que la libertad y la igualdad... sean reales y efectivas") sin que ni en sede doctrinal, ni en sede constitucional tales preceptos hayan sido objeto de cuestionamiento alguno como se ha producido ahora.

Y tampoco creo que el dato de que los derechos que consagran los nuevos Estatutos puedan funcionalmente operar como auténticos límites al poder de las respectivas Comunidades Autónomas pueda representar un obstáculo, en cuanto que pudiera interpretarse que contrarían la idea de autogobierno que late en la noción de "Estatuto de Autonomía" en cuanto norma institucional básica de la Comunidad. Ciertamente el Estatuto de Autonomía es materialización del derecho a la autonomía de las nacionalidades y regiones que consagra el art. $2 \mathrm{CE}$, esto es, el derecho de las poblaciones concernidas a la autodisposición de su propio gobierno dentro de los márgenes que la Constitución permite. Pues si de una parte el autogobierno no tiene por qué ser un proceso en constante expansión (si así fuera toda reforma estatutaria que no incrementara los niveles de autogobierno podría considerarse contraria a la Constitución), de otra, la facultad de autodisposición que el Estatuto materializa, comprende también de modo inexcusable la posibilidad de establecer nuevos límites al poder que se instaura o reforma. Lo contrario, llevado al extremo, obligaría a negar a las constituciones estatales la condición de ser expresión del autogobierno de las poblaciones afectadas porque incorporan declaraciones de derechos.

Un tercer y último interrogante que me parece que plantea el análisis de las cláusulas declarativas de derechos en los Estatutos es cual pueda ser la naturaleza, valor y eficacia de los derechos que allí se consagran, máxime si se tiene en cuenta que algún nuevo Estatuto (concretamente el catalán) contempla algunas vías adicionales de protección para tales derechos, vías que pasan por el obligatorio dictamen vinculante del denominado como Consejo de Garantías Estatutarias en aquellos procesos legislativos destinados a desarrollar el régimen jurídico de estos derechos estatutarios y por encomendar al Tribunal Superior de Justicia de la Comunidad el conocimiento de aquellos recursos que pudieran plantearse frente a eventuales vulneraciones de tales derechos.

No querría detenerme en esa concreta y, en mi opinión, cuestionable regulación del Estatuto de Cataluña, llena de ambigüedades y que solo puede ser un semillero de conflictos, porque no afectan al problema central del que me quiero ocupar, el valor jurídico de tales derechos.

Desde esa otra faceta, en cambio, sí que creo que es perceptible una cierta posición común en los diversos Estatutos de Autonomía ya reformados y que cuentan con ese tipo de cláusulas, pues todos ellos incorporan un precepto en el que parece latir una cierta relativización del valor de tales derechos, en torno a dos líneas: los derechos y principios proclamados en ningún caso suponen una alteración del régimen de distribución de competencias, y sus disposiciones nunca pueden ser desarrolladas, aplicadas o interpretadas de forma que reduzcan o limiten los derechos fundamentales reconocidos por la Constitución o por los tratados ratificados por España. 
Pero más expresivo aun que esa explícita proclamación que realizan los diversos textos estatutarios acerca de la naturaleza de tales derechos, quizás sea el dato que ofrece la lectura de los preceptos presuntamente declarativos de derechos, lectura que conduce a la conclusión de que, dada la textura normativa de los mismos, por más que se proclame explícitamente el carácter vinculante de los mismos para los poderes públicos, difícilmente puede colegirse que la mayor parte de tales enunciados — salvo los referidos a derechos lingüísticos- generen auténticamente derechos subjetivos, desenvolviéndose más precisamente en el terreno de las reservas de ley, mandatos al legislador, principios de actuación de los poderes públicos o criterios de interpretación del ordenamiento.

Ello en todo caso no significa que este tipo de normas carezcan absolutamente de eficacia y su proclamada fuerza vinculante esté vacía de todo contenido. Con toda evidencia dichos preceptos estatutarios se proyectan sobre la actuación de los poderes autonómicos respectivos, en particular sobre el legislador, lo que no deja de plantear algunos problemas dada la peculiar relación internormativa entre Estatuto y legislación autonómica. En efecto, como es sobradamente conocido, la ley autonómica, aunque ostente en cierta medida una posición jerárquicamente subordinada al Estatuto (lo que pareciera inducir a la resolución de los eventuales conflictos que entre ambos tipos de normas pudieran suscitarse mediante un juicio de mera legalidad) es lo cierto que sólo es anulable en sede constitucional, juicio de constitucionalidad que las instituciones autonómicas no están legitimadas a instar ante el Tribunal Constitucional, lo que confiere a los desarrollos legislativos autonómicos de los preceptos estatutarios aquí objeto de comentario de una posición singular.

No obstante, retomando de nuevo el tema desde un planteamiento general y contemplando el mismo desde la perspectiva que ofrece este tercer interrogante, tampoco aprecio dudas relevantes de constitucionalidad en este tipo de enunciados.

Pero, aceptada — en mi opinión - la legitimidad constitucional de las mismas, no por ello concluyo en una valoración positiva. No todo lo que no vulnera la Constitución es necesariamente funcional o técnicamente correcto. Y en relación al tema aquí comentado, como bien ha escrito Paloma Biglino, en palabras que comparto, el principal problema que plantean este tipo de cláusulas, hoy generalizadas a varios Estatutos de Autonomía, es eel espejismo que las mismas provocan, o dicho de otro modo, las falsas apariencias". Aparentan convertir el Estatuto de Autonomía en una especie de Constitución autonómica, aunque en verdad una y otra categoría no son asumibles. Aparentan constituir una tabla de derechos, cuando en verdad son mandatos al legislador o principios de actuación de los poderes públicos. Y aparentan elevar los niveles competenciales de la respectiva Comunidad Autónoma y en verdad establecen límites a los poderes públicos concernidos. Y provocar espejismos o falsas apariencias no me parece una técnica legislativa adecuada para el texto que es "la norma institucional básica" de una Comunidad Autónoma. 


\section{LUIS MARÍA DÍEZ-PICAZO}

Sobre las declaraciones estatutarias de derechos he escrito un artículo, aparecido en el núm. 78 de la Revista Española de Derecho Constitucional. Poco tengo que añadir a lo que allí dije. Básicamente pienso que, dado que los Estatutos de Autonomía han de ser finalmente aprobados por ley orgánica y que el papel del Congreso de los Diputados no es meramente de ratificación, la existencia de declaraciones estatutarias de derechos implica que un mismo legislador estima que un determinado bien o valor debe tener rango supralegal en ciertos territorios pero no en otros. Esto es irracional. Dicho esto, ninguna objeción tengo a que, en la medida de sus propias competencias materiales, las Comunidades Autónomas desarrollen una política legislativa de libertades públicas. Por usar un ejemplo claro: me parece bien que los legisladores autonómicos, si lo estiman conveniente, regulen el llamado "testamento vital"; pero esto no es lo mismo que introducir una norma estatutaria que obligue a ese legislador autonómico a reconocer el testamento vital. No sé qué dirá el Tribunal Constitucional. Pero, mientras llega su pronunciamiento a este respecto, sigo pensando que hay razones para dudar de la conformidad de las declaraciones estatutarias de derechos con la Constitución española.

\section{ÁNGEL GÓMEZ MONTORO}

Aunque pueda parecer obvio, antes de nada quiero aclarar que lo que diré a continuación parte de un análisis de lege lata, es decir, de la inclusión de derechos en los vigentes Estatutos y dentro del actual marco constitucional. Cuestión distinta sería, desde luego, el replanteamiento del modelo a partir de la voluntad de incluir declaraciones de derechos en las Normas institucionales básicas - llámense como se llamen: Estatutos o Constituciones- de las Comunidades Autónomas.

Pues bien, partiendo de estos presupuestos, comparto en gran medida las críticas formuladas por un importante sector de nuestra doctrina constitucional. Sin entrar ahora en si es posible o no que los Estatutos de Autonomía contengan un catálogo de derechos fundamentales, creo que esa inclusión aporta pocas ventajas y genera muchos inconvenientes desde el punto de vista de la aplicación o garantía de los derechos. De un lado, nuestra Constitución no ha previsto la coexistencia de la declaración de derechos de su Título I con otras equivalentes de los Estatutos de Autonomía y, por ello, tampoco ha establecido las fórmulas que en tal caso serían necesarias para delimitar la eficacia de ambos catálogos y resolver los problemas que necesariamente se derivarían de su concurrencia en el mismo territorio. El constituyente ha pensado en un único catálogo, estableciendo además los mecanismos que aseguran al Estado el desarrollo de los derechos (art. $81 \mathrm{CE}$ ) y las condiciones básicas de igualdad en su ejercicio (art. 149.1.1 CE), sin perjuicio 
de que las Comunidades Autónomas puedan establecer regulaciones que inciden en los derechos siempre que tengan competencia para ello y respeten dichos límites. El sistema es bastante complejo en sí mismo tal y como se ha visto a lo largo de estos casi treinta años, pero funciona a partir de estos supuestos.

La existencia de una carta autonómica de derechos incide de manera relevante sobre la aplicación de los derechos constitucionales sin que, como he dicho, existan mecanismos previstos para su correcta articulación. Para evitar estos problemas entiendo que no es suficiente con proclamar que el Título I de la Constitución seguirá prevaleciendo o que los derechos autonómicos sólo complementarán aquello que la Constitución no haya previsto o que vendrán a operar aportando mayores niveles de protección. Creo que tampoco vale con decir que estamos ante derechos subjetivos no fundamentales. Si se trata de normas que vinculan a los poderes públicos y, entre ellos, a los tribunales estos tendrán la obligación de interpretar los derechos constitucionales de acuerdos con los criterios y las concreciones que lleva a cabo el correspondiente Estatuto de Autonomía. Y esas concreciones reducen el margen de decisión del aplicador del Derecho y cierran en alguna medida el contenido dejado abierto por el constituyente. Máxime cuando, como ha ocurrido por ejemplo en el Estatuto catalán, las concreciones de algunos derechos responden a posicionamientos ideológicos que en muchos casos no son mayoritarios y sobre los que, en todo caso, no existe un suficiente consenso, tal y como han puesto de relieve los autores que se han pronunciado al respecto. Por otra parte, y como es bien sabido, las pretensiones de optimización de unos derechos se hacen muchas a costa de otros porque, con no poca frecuencia, los derechos compiten unos con otros (desde luego las libertades de expresión e información con los derechos de la personalidad, pero también el derecho a la igualdad en la educación con la libertad de enseñanza o el derecho de asociación de los socios con el derecho de autodeterminación que tienen las asociaciones a partir también del art. $22 \mathrm{CE}$, por citar sólo unos casos). Esto lleva consigo que los intentos de optimización de algunos derechos que se hace en los Estatutos de Autonomía supongan, en realidad, un entendimiento más limitado y restrictivo de otros derechos también previstos en el texto constitucional, lo que podría conducir a situaciones de desigualdad en el estatus básico de los españoles no compatibles con la Constitución.

Creo que lo que ocurre en el plano internacional es también suficientemente aleccionador: el entendimiento de los derechos garantizados en la Carta Europea de Derechos Humanos - e incluso ahora en la Carta de la UE y ello a pesar de que sólo tiene una eficacia interpretativa - viene en la práctica condicionando el entendimiento de los derechos por parte de los órganos jurisdiccionales españoles.

Ningún reparo tendría, sin embargo, si los Estatutos de Autonomía incluyeran no un catálogo de derechos y deberes sino normas relativas a las políticas públicas en materia de derechos, especialmente sociales y económicos, que pudieran orientar la actuación de los órganos autonómicos en el ámbito de sus 
competencias. Es muy posible que éste sea finalmente el entendimiento de las previsiones estatutarias pero, de ser así, hubiera sido preferible dejar clara esta opción y no suscitar espejismos - por utilizar la acertada expresión de la profesora Biglino- El Derecho no puede ni debe renunciar a aportar certeza y se contribuye poco a ello cuando las cosas no se llaman por su nombre.

\section{GREGORIO PECES-BARBA MARTÍNEZ}

Me parece absolutamente fuera de lugar. No puede haber derechos fundamentales distintos según los territorios y más bien se trata de ficciones que pretenden satisfacer el amor propio de esos territorios.

\section{JUAN JOSÉ SOLOZÁBAL ECHAVARRÍA}

La última cuestión a plantearme tratará de dar cuenta del sentido y límites de las declaraciones de derechos de los estatutos de autonomía según las reformas llevadas a cabo o las que se hallan en curso de tramitación. Inicialmente diré que mis consideraciones huirán de pronunciamientos holistas, así las que ofrecen una solución semántica al problema, aduciendo que no existe problema alguno, pues en realidad no tratamos de cuestiones que se planteen problemas de constitucionalidad, pues estamos ante declaraciones meramente estatutarias.Tampoco comparto la posición de quienes oponen una incompetencia total de los estatutos al respecto pues, la reserva absoluta del artículo $147 \mathrm{CE}$ no contempla la posibilidad de un contenido material de esta clase; o de quienes puedan negar trascendencia alguna a esta reforma, pues la preocupación estatutaria por atribuir consecuencias competenciales, como ocurre en el caso de la cláusula a estos efectos del tratado de la Unión, excluye este riesgo. Para otros, en una tesis que no asumo, este tipo de declaraciones no ofrece especial problema, habida cuenta de que la misma no sería consecuencia del despliegue de un poder constituyente soberano, del que por definición carecen las Comunidades Autónomas, que no poseen soberanía sino un poder de diferente naturaleza, o autonomía..

A mi juicio, ciertamente, por lo que se refiere a los derechos, no hay lugar a una actitud de mera oposición a la existencia de cláusulas de este tipo en los Estatutos de autonomía., siempre que se respete la igualdad de las posiciones jurídicas mínimas de este tipo en todo el territorio nacional, de manera que los Estatutos se limiten, especialmente en los derechos de configuración legal, a una labor de especificación y detalle. Ha de tratarse de una intervención contenida, sabiendo que la reiteración en los Estatutos de los derechos fundamentales sobre ser superflua $-\mathrm{y}$ debe recordarse así la recomendación del Tribunal Constitucional de que las normas jurídicas inferiores no repitan contenidos establecidos en otras superiores - conlleva un riesgo de degradación, o al menos de confusión, de su rango normativo. 
Esto es cierto pero ello no puede excluir absolutamente un reconocimiento estatutario de derechos fundamentales, en la medida en que tal prohibición no tendría sentido cuando, aunque con el límite del desarrollo de los mismos reservado a la ley orgánica y la regulación de las condiciones básicas del ejercicio de los derechos o posiciones jurídicas fundamentales a realizar por ley ordinaria estatal, según el art. 149.1.1. ${ }^{\circ}$, las Comunidades Autónomas pueden mediante ley normar la materia de los derechos fundamentales, de modo que, como se sabe, y ha reiterado el Tribunal Constitucional, desde la Sentencia sobre la Ley Vasca de Contratación de Cargas, los derechos fundamentales no se encuentran reservados al legislador estatal.

Ello quiere decir que especialmente en derechos de configuración legal, esto es, derechos políticos o derechos de participación y sociales, cabe siempre una especificación de los mismos por parte del Estatuto o decisiones de este orden sobre las condiciones de su ejercicio. Así al lado de recordatorios, perfectamente superfluos, sobre la disposición de los habitantes de una Comunidad autónoma de los derechos fundamentales establecidos en la Constitución - por ej. art. 9.1. ${ }^{\circ}$ del Estatuto vasco o antiguo art. 4.1. ${ }^{\circ}$ del Estatuto de Castilla La Mancha- los estatutos pueden desarrollar significativamente el principio de igualdad, garantizando expresamente la no discriminación por razón lingüística —art. 6-3. ${ }^{\circ}$ del Estatuto Vasco-; definir la condición política de los ciudadanos de la Comunidad correspondiente cuya posesión abre el disfrute de la participación política en la misma; o establecer modalidades de intervención en la vida pública sobre bases más amplias que las previstas en el ordenamiento general, así, por ejemplo, mediante una regulación más generosa de la iniciativa legislativa o de las convocatorias de referendum. Esto es tan obvio como obvia es también la contribución del legislador estatutario y del legislador autonómico a la realización de políticas de favorecimiento de los derechos fundamentales, especialmente en el caso de los derechos sociales, que - por cierto - a mi juicio son derechos fundamentales.

La Constitución difiere el régimen de las lenguas españolas a los estatutos de autonomía, aunque asegurando la condición del castellano como lengua oficial del Estado e imponiendo el deber de conocerlo y el derecho a usarlo. La significación simbólica de las lenguas propias y su importancia en la vida de la Comunidad que el Estatuto regula explica que tal norma adopte las decisiones básicas sobre esta materia, a completarse sin duda en una reglamentación general o particular en cada cuestión concreta por el legislador autonómico. La cuestión está en si el Estatuto como hace el catalán puede imponer su conocimiento (art. 6). A mi juicio ello es dudoso. En primer lugar porque la imposición de tal deber alteraría la imagen maestra del bilingüismo establecida en la Constitución en la que tal obligación del conocimiento se establece sólo para el castellano. Así, constitucionalmente no cabe la imposición por parte de la Comunidad Autónoma del conocimiento de la lengua propia, pues, como ha establecido el Tribunal Constitucional en la STC 82/1986, "Sólo del castellano se establece constitucionalmente un deber individualizado de conocimiento, y con él, la presunción de que todos los españoles lo co- 
nocen". Además, el modelo estatutario podría poner en grave riesgo la igualdad de los ciudadanos catalanes en el acceso y disfrute de las prestaciones, si se restringe el empleo del castellano a las relaciones singularizadas con la Administración, en base a la pesunción de conocimiento del catalán a deducir de la obligación estatutariamente establecida de su conocimiento, y no se obliga a la Generalitat a ofrecer en los dos idiomas sus servicios. De modo que la utilización del bilingüismo en los servicios públicos no sólo es exigencia deducida de la obligación de protección a las lenguas, que conlleva su cooficialidad, sino consecuencia de la existencia de quienes no conocen, o pueden no conocer, la lengua de la Comunidad, que se encontrarían en situación de desventaja e incluso de discriminación si algunas asistencias, en razón de las condiciones idiomáticas en que se prestan, no les fuesen accesibles, o su acceso se produjera en términos deficientes.

Me parece, evidentemente, que frente a las alegaciones de inconstitucionalidad contra el Estatuto por su tratamiento de la cuestión lingüística poca entidad ofrece apuntar a la inanidad estatutaria de la imposición del deber del conocimiento del catalán, pues tal cláusula tendría un valor meramente programático o "impropio", y por otra parte la afirmación estatutaria no haría sino recoger, elevando el rango, la situación del catalán en las leyes sobre el particular existentes ya en la Comunidad. Creo que a estas alturas no es necesario insistir en la inexistencia de cláusulas meramente programáticas o retóricas en ningún texto constitucional, y el Estatuto tiene ciertamente este carácter. De otro lado, el deber de conocimiento del catalán, como todo el mundo sabe, no es sino un primer paso de desarrollo en esa materia, cuya legitimación tendrá una renovada base, además de mayor rango normativo.

\section{CRITERIOS DE LIMITACIÓN DE LOS DERECHOS}

6. "Sabemos que para establecer los "limites de los límites" de los derechos fundamentales el TC acude a los principios de racionalidad y proporcionalidad y al criterio de la ponderación. ¿Nos puede dar su opinión sobre la problemática de estas pautas y sobre si le parecen objetivables y que de su empleo puede desprenderse previsibilidad y certeza?

\section{LUIS AGUIAR DE LUQUE}

Probablemente uno de los problemas de la teoría de los derechos fundamentales que mayores dificultades encierra (y también con relevantes implicaciones prácticas) es el que deriva de aquella frase aparentemente inocua y casi obvia que el Tribunal Constitucional proclamó en dos de sus primeras sentencias (SSTC 11/81 y 2/82) para referirse a las eventuales restricciones que pudieran imponerse a los derechos fundamentales, sea con carácter general sea de modo particular. "Todo derecho tiene sus límites... pues ningún dere- 
cho, ni aun los de naturaleza o carácter constitucional pueden considerarse ilimitados" dijo entonces el Tribunal Constitucional. Pronunciamiento a partir del cual tanto la doctrina académica como la jurisprudencia constitucional ulterior se han esforzado en prolongar a fin de elaborar una teoría de los límites de los derechos fundamentales en cuya formulación concurren algunos de los elementos centrales para la determinación del régimen jurídico de tales derechos como los de "regulación del ejercicio" de un derecho o determinación de su contenido, "reserva de ley" en esta materia o "contenido esencial", expresiones tan polisémicas como "límites", "delimitación" o "restricción" de los derechos, o construcciones jurídicas tan sofisticadas como los "principios de proporcionalidad y racionalidad", o "juicio de ponderación".

Pues bien, es en este contexto de intentar construir una teoría constitucionalmente adecuada de los límites de los derechos fundamentales donde surge y se desarrolla el "principio de proporcionalidad" que el Tribunal Constitucional adopta siguiendo la estela de la elaboración llevada a cabo por el Tribunal Europeo de Derechos Humanos, el Tribunal de Justicia de las Comunidades Europeas, así como la doctrina sentada por diversas cortes constitucionales europeas, singularmente el Tribunal Constitucional alemán.

En todo caso hay que comenzar señalando que la primera doctrina del Tribunal Constitucional de nuestro país en esta materia responde más a una utilización un tanto intuitiva, espontánea, no formalizada, aludiendo a un principio de proporcionalidad no estrictamente identificable con el contenido que se viene reconociendo al mismo en el momento actual (de clara inspiración alemana); o dicho en otros términos, en ese primer recurso a dicho principio (quizás más ajustadamente habría que decir a dicha expresión) éste/a aparece como sinónimo o intercambiable, ${ }^{\text {i) }} \mathrm{Con}$ la exigible razonabilidad que debe acompañar toda actuación pública restrictiva, en especial, en materia de derechos fundamentales, ii) con la adecuación de la medida limitativa, de su necesidad, ${ }^{\text {iii }}$ con el examen de la finalidad de la misma (finalidad, que, hoy, como se dirá más adelante, de forma más depurada, constituye para el Tribunal un prius a la utilización del principio de proporcionalidad) o, finalmente, iv) $\mathrm{con}$ la ponderación entre el derecho sacrificado y el bien o derecho protegido.

En definitiva, un uso del principio que, en otras ocasiones, ni siquiera merecía al Tribunal mención específica como criterio interpretativo y que, en todo caso, se mostraba de contornos y contenido difuso e identificado con alguno o algunos de sus elementos actuales, pero sin realizar un examen concreto de cada uno de ellos, de forma sucesiva, como hoy entendemos el principio de proporcionalidad.

En todo caso, algún autor singularmente estudioso de esta cuestión, como González Beilfuss, valorando positivamente la depuración dogmática realizada por el Tribunal en la jurisprudencia ulterior, advierte que todavía, en ocasiones, retrocede a la práctica anterior de una proporcionalidad más pragmática y espontánea frente a la construcción formalizada dotada de contenido jurídico-normativo, si bien, el citado autor admite las dificultades para dotar a un principio de este tipo de un contorno rígidamente formalizado. 
¿Cuál es el ámbito y finalidad en el que se desenvuelve el desarrollo de este principio de proporcionalidad como categoría hoy central de la teoría de los límites de los derechos fundamentales?

Intentando simplificar el tema y partiendo de la constatación antes reseñada de que «todo derecho se halla sometido a límites (eludo ahora entrar en la controvertida disquisición acerca del distinto significado de expresiones tales como "delimitación" o "restricción" de derechos) la potestad limitadora se halla igualmente sometida a límites, limites de los límites que, más allá de conceptos absolutizadores o estáticos como puede ser el del "contenido esencial" (en algunas de las interpretaciones de dicha expresión), se depuran mediante un juicio de contraste o ponderación entre los intereses, bienes o valores en presencia que gozan de respaldo constitucional (habitualmente intereses públicos y derechos e intereses particulares). Dicha actitud metodológica parece, por lo demás, particularmente adecuada si se tiene en cuenta que la formulación constitucional de los derechos corresponde en gran medida a la noción de "principios y no de "reglas" de tal modo que, como ha apuntado L. M. ${ }^{a}$. Díez Picazo, la aplicación de los derechos fundamentales no se realiza a través de la técnica de la subsunción, sino acudiendo a criterios interpretativos integradores que ponderen las diferentes dimensiones afectadas y que sean capaces de articular la composición y el equilibrio de los elementos diversos de un sistema en una conexión de sentido.

En este sentido, el recurso al principio de proporcionalidad, tal como lo realiza el Tribunal Constitucional en la actualidad, esto es, mediante una elaboración notablemente más depurada en la que se distingue y analiza sucesivamente los requisitos de idoneidad, necesidad y proporcionalidad en sentido estricto, como elementos diferenciados e integrantes todos ellos del principio de proporcionalidad, y que, con algún retroceso hacia una línea anterior menos formalizada, parece caracterizar la jurisprudencia constitucional a partir de la segunda mitad de la década de los noventa, permite clarificar el contenido de este principio y definir sus contornos jurídicos de forma más precisa, favoreciendo así un mayor grado de previsibilidad y certeza.

Ciertamente esta mayor previsibilidad del resultado que depara la aplicación del principio de proporcionalidad queda en todo caso enormemente condicionada por lo concreto y casuístico del objeto sometido a control (la posible conculcación de los derechos fundamentales, en un procedimiento de amparo), vinculado necesariamente a las circunstancias fácticas del caso, que pueden convertirse en elementos determinantes en el análisis de cada uno de los requisitos que incorpora el principio de proporcionalidad (aunque, como se verá, en puridad, el análisis factual debiera realizarse en sede de idoneidad de la medida, el primero de los subprincipios que configuran el principio de proporcionalidad).

El principio de proporcionalidad, como criterio de interpretación en el ámbito de los derechos fundamentales, sirve así a la consideración, o exclusión, de la constitucionalidad de la medida restrictiva de derechos fundamentales, dado el análisis de su idoneidad, necesidad, y proporcionalidad en sentido es- 
tricto. En el bien entendido que cada uno de estos subprincipios, que en ocasiones personifican el principio de proporcionalidad, son distintos, proyectándose y afectando también a cuestiones, y elementos diferentes de la medida restrictiva. Sin perjuicio de que todos ellos integran el principio de proporcionalidad como habitualmente se define.

Con carácter previo al análisis de cada uno de estos subprincipios, el examen de la proporcionalidad ha de corresponder con la valoración de la finalidad perseguida con la restricción del derecho (el "prius" del principio de proporcionalidad que llama el Tribunal). Dicha finalidad debe reputarse constitucional para proceder a la aplicación del principio de proporcionalidad a la misma, pues, en caso contrario, quedará de plano excluida y consecuentemente declarada como vulneradora del derecho individual alegado. El Tribunal en este juicio viene exigiendo la legitimidad constitucional de la finalidad, vinculando ésta con la existencia de un bien jurídico constitucional cuya protección perseguiría la medida objeto de control.

Superado este primer test la restricción se valora de forma sucesiva en cuanto a su idoneidad, necesidad y proporcionalidad estricta, a saber, si la medida,

i) resulta adecuada para conseguir la finalidad pretendida (juicio de idoneidad), juicio de causalidad que pone en relación restricción concreta del derecho y finalidad de tal restricción atendiendo de forma destacada a las circunstancias fácticas del caso, de su capacidad para obtener un fin predeterminado y constitucional, y al que el Tribunal en ocasiones se refiere como razonabilidad de la medida restrictiva;

ii) es el medio de los posibles menos gravoso para los derechos individuales y ofrece la misma eficacia para proteger el bien jurídico que constituye la finalidad de la restricción (juicio de necesidad), por tanto, funge a la comparación de la medida concreta adoptada con otras alternativas posibles para conseguir la misma finalidad; y

iii) resulta proporcional a la finalidad protegida, si cabe deducir una relación de equilibrio entre el medio restrictivo aplicado y la finalidad del mismo, comparando aquí la entidad de cada uno de tales elementos (restricción y objetivo buscado), y utilizando a estos efectos como técnica principal la ponderación (criterio que es aplicado de forma destacada en la resolución de conflictos entre derechos fundamentales de igual valor, consideración y jerarquía constitucional, de igual identidad, como el habitual entre libertades de expresión e información y derechos de la personalidad, los reconocidos en los arts. 20 y $18 \mathrm{CE}$ ).

De lo antedicho, cabe concluir que el principio de proporcionalidad es un criterio de interpretación, instrumental, de carácter relacional que analiza la medida restrictiva desde la finalidad perseguida con la misma (a diferencia del principio de igualdad que incluye en el término de comparación una relación internormativa, y que, exige la propia proporcionalidad de la diferencia de trato respecto a la finalidad de este régimen jurídico distinto), condicionado por las circunstancias fácticas del caso (lo que de suyo limita la certidumbre y la pre- 
visibilidad de su aplicación, y dificulta su utilización como parámetro de control en los procedimientos abstractos de constitucionalidad), negativo, en cuanto que para concluir la inconstitucionalidad de la restricción no se exige que la medida objeto de control sea la más proporcional, sino que no lleve a la desproporción, incluye, pues, una "prohibición de exceso"; máxime si se trata de enjuiciar la obra del legislador, la ley, en cuyo caso el Tribunal ha reconocido de forma tajante el mayor margen de actuación del legislador y la menor intensidad, incisividad, del control con que ha de efectuar su valoración (constituyendo estos supuestos terreno abonado para las sentencias interpretativas).

En suma, creo que el recurso al principio de proporcionalidad como criterio interpretativo de los derechos fundamentales ante eventuales intervenciones públicas que pudieran desvirtuar su significado aporta un más alto grado de objetivación de los criterios de interpretación y aplicación de los derechos, en particular tras el esfuerzo de depuración llevado a cabo por el Tribunal Constitucional en su jurisprudencia.

\section{LUIS MARÍA DÍEZ-PICAZO}

A esta pregunta le daría una triple respuesta. En primer lugar, creo que el abandono de facto por parte de la jurisprudencia constitucional del "contenido esencial", de que habla el artículo 53.1 de la Constitución, como límite a las restricciones de los derechos fundamentales ha sido positivo. Y ello porque la idea de contenido esencial, mal copiada de Alemania como mostró en su día Ignacio de Otto, es esencialmente confusa. Es mejor seguir la pauta de la mayor parte de los tribunales constitucionales y supranacionales, que se guían por la idea de balancing o ponderación.

En segundo lugar, la ponderación admite un notable grado de tecnificación, aunque seguramente no puede pretenderse que dé lugar siempre a soluciones totalmente predecibles. Si esta absoluta previsibilidad no es posible con la subsunción, que es el modo de aplicar las "reglas", no es razonable esperarla de la ponderación, que es el modo de aplicar los "principios". Dicho esto, creo que el principal problema de la ponderación es determinar con qué se ponderan los derechos fundamentales, es decir, qué se pone en el otro platillo de la balanza: ¿sólo otros derechos fundamentales u otros valores de rango constitucional, o también cualesquiera intereses generales dignos de protección? Siendo realistas, resulta difícil sostener que los derechos fundamentales sólo pueden ser restringidos en nombre de otros valores de rango constitucional, por lo que hay que dejar la puerta abierta a su restricción en nombre de otros objetivos; pero esto plantea el problema de determinar cuándo esos objetivos sin cobertura constitucional son lo suficientemente importantes como para limitar derechos fundamentales. Es aquí donde las visiones del mundo de cada intérprete juegan un papel crucial. Ahora bien, una vez admitido que el objetivo de que se trate es digno de entrar en ponderación con un derecho fundamental, la ponderación en cuanto tal 
plantea normalmente menos dificultades. Se trata básicamente de comprobar cuál de los dos valores en liza está, en las circunstancias concretas, más en peligro en sus aspectos esenciales o nucleares y, por tanto, es más digno de protección en dichas circunstancias.

En tercer lugar, con respecto al principio de proporcionalidad, hay que recordar que no es una técnica específica de los derechos fundamentales, sino que entra en juego en otros sectores del ordenamiento jurídico, como es destacadamente el derecho administrativo, siempre que hay interferencias en situaciones de libertad o propiedad. La idea es que la interferencia debe ser sólo la indispensable para alcanzar el fin perseguido. Lo que exceda de ello será tachado de desproporcionado. La tecnificación del principio de proporcionalidad pasa, así, por argumentar que habría habido un medio menos gravoso de alcanzar el fin propuesto. Sin embargo, que en su versión alemana, que es la más conocida, el principio de proporcionalidad no se limita a esto, sino que incluye también la llamada "proporcionalidad en sentido estricto"; es decir, aun cuando no haya medio menos gravoso, la intromisión no debe ser excesiva. Confieso que nunca he comprendido bien el significado de este requisito adicional del principio de proporcionalidad more germanico.

\section{ÁNGEL GÓMEZ MONTORO}

Entiendo que esos métodos y principios son insoslayables a la hora de aplicar los derechos fundamentales, al examinar sus límites o al resolver las colisiones entre derechos. Por otra parte, no me cuesta mucho entender la desazón que a veces produce entre los ciudadanos e incluso entre los juristas, la sensación de imprevisibilidad de las decisiones judiciales; el desconcierto ante soluciones jurisdiccionales distintas — cuando no diametralmente opuestas- en las diversas instancias que se pronuncian sobre un asunto o, incluso, el contraste de pareceres entre la mayoría del Tribunal Constitucional que aprueba una sentencia y los magistrados que firman votos particulares. Pienso que no debe escandalizar la existencia de un margen de decisión pero al mismo tiempo los actores jurídicos deberían extremar el rigor a la hora de aplicar estos principios.

De un lado, es necesario apurar al máximo las ponderaciones que muchas veces ha hecho ya el propio constituyente y, cuando existan, las que puede haber llevado a cabo el legislador en relación con ciertas limitaciones de derechos o a la hora de aportar soluciones sobre las posibles colisiones entre ellos (por ejemplo en las relaciones entre trabajador o empresario, etc.). Los órganos jurisdiccionales deberían ser respetuosos en tales casos con la letra de los preceptos evitando forzar su tenor literal en aras a soluciones que puedan considerar más adecuadas.

Por otra parte, debería extremarse el rigor a la hora de aplicar los distintos pasos de cada uno de estos métodos (juicio de idoneidad, de necesidad, etc.), llevando el razonamiento hasta donde sea posible y explicitando incluso 
cada uno de los ellos. He de reconocer que a veces echo en falta el rigor con que la doctrina y la jurisprudencia alemana suele aplicar los tests de control. Pienso incluso si no deberíamos ir introduciendo fórmulas de vinculación a los precedentes que aporten cierta certeza. No deja de llamar la atención que hayamos importado en materia de derechos fundamentales tantas soluciones propias del case Law americano y sin embargo ignoremos el rigor con que los tribunales examinan allí las soluciones aportadas previamente y el esfuerzo que llevan a cabo para justificar cualquier decisión que pueda alejarse de ellas.

En todo caso, todos los operadores jurídicos deberíamos esforzarnos para que la ductilidad propia del Derecho de los derechos fundamentales no se convierta en mera libertad para decidir lo que en cada caso parece más conveniente al margen de las técnicas propias de la aplicación de los derechos.

\section{GREGORIO PECES-BARBA MARTÍNEZ}

Son pautas vinculadas a principios y éstos no tienen la certeza que tienen las reglas. Por consiguiente, la aequitas cerebrina de los jueces tiene un papel excesivo y que desde luego no está precisamente en la línea de la seguridad jurídica. Los principios tienen siempre una textura abierta que les hace muy dependientes de la voluntad de los jueces.

\section{JUAN JOSÉ SOLOZÁBAL ECHAVARRÍA}

\section{La cuestión de la limitación de los derechos:}

\section{A) el contenido esencial}

Sabido es que los problemas más interesantes que presentan los derechos fundamentales se refieren a su limitación, exigida del aseguramiento de su ejercicio en un ordenamiento que debe de garantizar, simultáneamente, el disfrute de ese derecho por parte de los demás y las exigencias de respeto de otros derechos y bienes jurídico constitucionales. Durante mucho tiempo se entendió que, atendidos los mismos términos de su reconocimiento constitucional, en el que puede ya descubrirse una configuración del derecho, los problemas de la limitación se salvaban con la observancia del contenido esencial, como límite de límites. Los problemas que plantea la caracterización del contenido esencial no son menores. Como se sabe el Tribunal Constitucional realizó una descripción, desde un punto de vista técnico, de su contenido y utilizó esta referencia como parámetro de control en numerosísimas ocasiones respecto de la contención o licitud constitucional de la regulación legislativa mismo. Pero los problemas de esta categoría no son pequeños, Comenzando con su condición tautológica o, si se quiere decir en términos me- 
nos contundentes, declarativos de la misma, que no dejaban de operar un tanto en la característica fundamental de la Constitución como es su normatividad. En efecto la exigencia al respeto del contenido esencial no implicaba otra cosa a la postre que una prohibición desfiguradora del legislador, pero dicha prohibición ni operaba sólo en el caso previsto en el artículo $53 \mathrm{CE}$, sino sobre todo en el caso de las leyes orgánicas de desarrollo, y también, si se aceptase la idea de una actuación limitada de la reforma constitucional, como yo creo que es la posición correcta, ante el propio poder constituyente constituido. Ahora bien tal límite no procedía de la estipulación establecida en la Carta Constitucional, sino de la posición de la Constitución respecto del resto del ordenamiento y sobre todo de la ley. De otro lado esa subordinación impedía la disposición del contenido constitucional en todo caso, estuviésemos o no ante un derecho fundamental del capítulo $2 .^{\circ}$ o una figura de otro tipo, por ejemplo, una garantía institucional o una prestación con la estructura normativa de un verdadero derecho. De otro lado seguramente las exigencias concretas del respeto del contenido esencial se plantean de diversa manera según nos encontremos ante actuaciones del legislador o de los jueces. En cualquier caso la virtualidad del principio desaparece cuando el conflicto entre derechos se produce en términos en que no es posible la composición, a través de una actuación de ponderación que lleva a la "concordancia práctica", sino que sólo es resoluble en términos de prevalencia. En tales ejemplos, como decimos, el del contenido esencial no es un límite absoluto que proteja en caso de conflicto a los derechos en pugna, porque hay conflictos sencillamente no resolubles por medio de la acomodación sino, en ese supuesto concreto y no de modo permanente o incondicionado, a través de la imposición del derecho prevalente. La situación no parece resolverse, a través de nominalismos, como aquel en que se incurre si se afirma que el derecho que cede, y que en ese supuesto concreto se retira, sigue atribuyéndose en su titularidad a su dueño, de modo que sólo lo perdería en el ejercicio. Lo que sí parece, en todo caso, es que el límite del contenido esencial opera como un mandato de optimización de los derechos, al afirmarse, en principio el acomodo de los mismos.

\section{B) el principio de proporcionalidad}

Las dificultades que presenta la utilización del principio del contenido esencial como criterio a través del que resolver las cuestiones sobre la constitucionalidad de la limitación de los derechos, han acabado determinando su sustitución por la aplicación del principio de proporcionalidad a dicho efecto. Sin duda pronunciarse acerca de la conveniencia de su inclusión en la Constitución, como ocurría en el Tratado Constitucional de la Unión Europea, puede hacer conveniente dedicar una mínima atención a tal principio. Su sentido general se capta caracterizándolo como un principio técnico de control de la arbitrariedad del legislador. Proporcionalidad quiere decir para el legislador 
que las regulaciones y habilitaciones legales con un significado invasor de los derechos fundamentales deben ser apropiadas y necesarias para alcanzar su finalidad respectiva, que a su vez debe ser constitucionalmente legítima. Sin embargo el propósito primero del principio no era el control del legislador sino el de la administración, lo que nuevamente puede volver a ocurrir en determinados ámbitos materiales cuando las exigencias del principio de legalidad se contraen a habilitar, pero no a guiarla propiamente, la intervención del reglamento.

El principio de la proporcionalidad se presenta originariamente como un criterio de control del poder discrecional de la Administración (sobre todo la policial). Más tarde completará el canon de constitucionalidad como principio implícito del orden constitucional (subprincipio sobre todo del Estado de derecho), de manera que la suerte de los derechos no quede sólo protegida ante la Administración mediante el expediente de la reserva, lo que excluirá un reglamento independiente o una deslegalización de esta materia. Nuevamente en nuestros días el principio revierte a su primer sentido como medio jurídico de control de la Administración pues, dadas las condiciones en que se enmarca la actuación reglamentaria, esta cada vez cuenta con un mayor espacio de discrecionalidad. Así la ley, especialmente si no se encuentra impuesta por una reserva constitucional, no tiene por objeto, dada su indefinición, cubrir la actuación de la Administración, esto es guiarla, preverla o controlarla, sino habilitarla o hacerla posible, de manera que la determinación de su alcance está en manos de la propia Administración y su control no puede hacerse ya a partir de la norma legal sino de criterios externos, básicamente el respeto de la proporcionalidad.

Naturalmente de lo que se trata es de explorar la configuración del parámetro de control del legislador con el principio de proporcionalidad que expresamente no viene recogido en la Constitución, lo que no ha arredado a nuestro Tribunal constitucional para su utilización en materia penal, sirviéndole en dos de los tres amparos más importantes sobre la cuestión para desestimar el recurso, mientras basa en tal criterio la sentencia estimatoria en el caso de la Mesa Nacional de Herri Batasuna (STC 13/1999) por considerar desproporcionada la pena establecida en el Código penal por colaboración con banda armada u organización terrorista..

En las tres Sentencias (además de la citada, las STC 55/1996 y 161/1997) se acoge un criterio técnico de proporcionalidad en el campo penal que exige que exista relación entre la gravedad de la infracción y la entidad de la pena. Se entiende que el legislador se ha atenido al principio siempre que la pena se justifique aplicando el test de la proporcionalidad, esto es, que exista necesidad de tipificación penal, dado el ataque que sufre el bien jurídico correspondiente, que la medida sea adecuada y, por último, que suponga una intervención mínima que no ponga en peligro la adecuación o idoneidad, así como la necesidad o justificación de la medida.

El Tribunal sólo puede controlar la proporcionalidad de la pena en casos extremos, ya porque la intervención penal no esté justificada o porque la mis- 
ma sea manifiestamente excesiva. Así no procede la revisión jurisdiccional en los dos primeros casos aludidos en los que, efectivamente, se desestiman los amparos. Pero sí debe verificarse el control en el tercero de los supuestos, toda vez que la conducta castigada — se trataba de la cesión del espacio electoral correspondiente a HB a la organización terrorista ETA - sin poder exhibir causa de justificación, si que sufre un rigor inconstitucional, dado el mayor margen de la libertad de expresión durante los periodos electorales y los efectos inhibitorios que un castigo penal como el tipificado ha de tener sobre el ejercicio de derechos fundamentales como la libertad de asociación y expresión ${ }^{1}$.

La experiencia de la utilización de este criterio de actuación del Tribunal Constitucional lo que muestra es el peligro de la utilización como parámetro de constitucionalidad no ya de prescripciones constitucionales concretas, sino pautas de simple razonabilidad, que, a pesar de su aparente presentación técnica, amenaza con inhibir facultades de creación normativa que a quien corresponden verdaderamente es al legislador.

\section{DERECHOS Y RELACIONES ENTRE PARTICULARES}

7. ¿ ¿Cómo enfocaría Vd. la cuestión de la eficacia de los derechos fundamentales en las relaciones entre particulares?

\section{LUIS AGUIAR DE LUQUE}

El problema de la eficacia de los derechos fundamentales en las relaciones entre particulares es hoy en buena medida un asunto resuelto en el terreno práctico. Primero el Tribunal Constitucional con una jurisprudencia muy activa en este tema desde los primeros momentos (recuérdese la inolvidable sentencia 38/81 — ponente J. Arozamena - y la construcción de la noción de "despido nulo con nulidad radical") y, más tarde, la jurisdicción ordinaria, han superado el encorsetamiento que parecía imponer la LOTC (en particular el art. 41.2) al contemplar exclusivamente el amparo como un remedio a las vio-

1 En realidad esta sentencia sobre la Mesa Nacional de HB es severamente discutible en sus bases doctrinales. Primero, porque el principio de proporcionalidad es un principio constitucional implícito que difícilmente puede operar como canon separado y abstracto de constitucionalidad, que es lo que ocurre en esta sentencia, a pesar de las observaciones y protestas en ese sentido del propio Tribunal. Y, en segundo lugar, porque la decisión sobre la procedencia y, en su caso, alcance de la penalización, de acuerdo con el criterio sentado por el propio Tribunal, es de naturaleza política y técnica y debe estar en manos del legislador.

En este caso concreto además, la decisión del Tribunal Constitucional es cuestionable, pues ni puede aceptarse que durante el período electoral desaparezcan los límites a la libertad de expresión, ni parece admisible que el castigo del abuso de la libertad de expresión se considere inhibitorio del ejercicio de la misma. 
laciones de los derechos fundamentales provenientes de actos de los poderes públicos, lo que sensu contrario parecía presuponer que la violación de un derecho fundamental no podía provenir de los particulares por la simple razón de que éstos, en cuanto tales y directamente, no regían las relaciones entre éstos últimos.

No obstante, la superación de las precitadas dificultades procesales, y con ello la pérdida de interés práctico de esta cuestión, no creo que haya mermado el interés teórico de la misma desde perspectivas constitucionales. Aunque sólo sea por las implicaciones que tiene en la reflexión sobre este tema la idea misma de Constitución y el significado de los derechos fundamentales en la vida jurídica, idea por lo demás en la que es perceptible una clara evolución desde los primeros años de vigencia de nuestro texto constitucional a la actualidad.

En efecto, ciertamente las dificultades que en los años 80 existían para admitir la eficacia de los derechos fundamentales en las relaciones entre privados derivaban inmediatamente de la LOTC, tal como se acaba de exponer, pues la Constitución nada dice de modo explícito al respecto (incluso quizás cupiera entender que nuestro texto constitucional contiene más elementos favorables para propiciar una eficacia horizontal de los derechos fundamentales que otros textos constitucionales de nuestro entorno; así la alusión explícita a la vinculación a la Constitución de los ciudadanos del art. 9.1 o la igualmente expresa - aunque fuese a contrario- de la aplicabilidad directa de tales derechos que se contiene en el art. 53.3).

Sin embargo es lo cierto que la doctrina constitucional mayoritaria en el momento de elaborarse la Constitución (y probablemente también entre nuestros constituyentes) era la propia del constitucionalismo liberal que básicamente concibe los derechos que la Constitución proclama como límites frente al poder y que, congruentemente, entiende que éstos solo son eficaces para regular las relaciones entre el ciudadano y los poderes públicos. La elaboración de la categoría "derechos públicos subjetivos" como intento de formalizar doctrinalmente estos derechos es buena prueba de ello. En sentido contrario, desde dicho modo de entender la Constitución, los derechos fundamentales no están previstos para conformar las relaciones de los ciudadanos entre sí, relaciones que están exclusivamente regidas por el ordenamiento jurídico privado de rango infraconstitucional presidido el principio de autonomía de la voluntad. No deja de ser significativo de esta "resistencia" del constitucionalismo liberal a admitir una cierta eficacia de los derechos fundamentales en las relaciones entre particulares que, hasta donde mis conocimientos alcanzan, la primera ocasión en la que el mundo jurídico-académico se preocupa monográficamente por una hipotética eficacia de los derechos en este ámbito es el libro homenaje a René Cassin publicado en 1970 que dedica el volumen III a "La protection des droits de l'homme dans les rapports entre personnes privées".

En estas circunstancias no es extraño que también entre los constitucionalistas españoles de principios de los 80 la opinión dominante fuera contra- 
ria a una eventual eficacia directa de los derechos fundamentales y se defendiese tan solo una eficacia exclusivamente mediata, esto es, canalizada a través de la previa intervención del legislador.

Sin embargo me atrevería a decir que, con el transcurso de los años, esta posición ha cambiado sustancialmente hasta el punto de que hoy, con carácter general, el enfoque a la hora de analizar esta cuestión debe ser otro.

Obviamente no es ajeno a ello el cambio de perspectiva respecto al significado y valor de los derechos que la Constitución consagra, cambio de perspectiva al que hacía alusión en la respuesta a la primera de las cuestiones aquí planteadas. Pero lo cierto es que los derechos fundamentales para el constitucionalismo actual (o al menos para constitucionalismo español) no son solo límites a los poderes públicos. Como elementos del orden objetivo, se incorporan plenamente al ordenamiento positivo, confieren a los ciudadanos auténticos derechos subjetivos de carácter omnidireccional y proyectan su eficacia sobre los más variados sectores del ordenamiento,

La "fuerza de irradiación" de la que hablara el Tribunal Constitucional Alemán en el conocido caso Lüth (1958), se ha traducido en nuestra práctica jurídica en una predisposición favorable a que los derechos fundamentales proyecten su fuerza conformadora sobre la realidad social y, por tanto, también sobre las relaciones de carácter jurídico que puedan establecer los particulares.

El resultado, en todo caso, no puede ser una indiscriminada eficacia de los derechos fundamentales en las relaciones entre privados. Con carácter ordinario corresponde al legislador, expresión de las mayorías político-parlamentarias del momento, determinar el grado de vinculación de los particulares a los principios y valores constitucionales. Pero frente al recelo y desconfianza con que se contemplaba en el pasado la eficacia inmediata y directa de los derechos fundamentales al mundo privado y sus relaciones, hoy creo que se puede constatar una más clara apertura a esa posibilidad. Principalmente en sede judicial (sea por la jurisdicción ordinaria, sea por la constitucional a través del recurso de amparo) como instrumento de modulación de relaciones jurídico-privadas, posibilitando una correcta ponderación de los intereses y derechos en presencia. Aplicación, por lo demás, que ciertamente no puede tener carácter general, sino que se ha de modular en función del derecho constitucional concernido, el tipo de relación sobre la que se proyecta (las relaciones laborales son un lugar privilegiado para que esa eficacia inmediata tenga lugar, según tiene bien acreditado la jurisprudencia constitucional) y los sujetos-actores de la relación sobre la que se plantea el debate judicial.

Pero lo que me parece relevante como expresión de este cambio de paradigma es que, llegado el caso, la instancia judicial competente tampoco tiene que dar sin más carta de legitimidad constitucional a determinadas relaciones jurídicas que pueden representar un total vaciamiento de los derechos fundamentales en el ámbito privado, con el mero apoyo de que tales derechos carecen de eficacia directa en las relaciones entre particulares. 


\section{LUIS MARÍA DÍEZ-PICAZO}

Mi opinión sobre este tema es que resulta muy difícil de examinar en abstracto. Es mucho más fácil debatir sobre la eficacia horizontal refiriéndose a cuestiones concretas. Sentada esta premisa, creo que la regla general debe ser que los derechos fundamentales limitan al Estado, no a los particulares. Las relaciones privadas, en una sociedad liberal-democrática, deben estar presididas, en principio, por la idea de autonomía de la voluntad. Pero ello no obsta a que, dada la finalidad y la estructura de determinados derechos fundamentales, a veces éstos puedan y deban desplegar cierta eficacia entre particulares. Piénsese, por ejemplo, en la libertad de asociación.

Luego está el problema de las relaciones que, aun siendo privadas, se caracterizan por su desigualdad. Tal es paradigmáticamente el caso de las relaciones laborales. Aquí pienso que frecuentemente hay buenas razones para sostener la eficacia horizontal de los derechos fundamentales, aunque siempre se debe ser prudentes: tratándose de relaciones privadas, la carga de la argumentación debe pesar sobre quien pretende la aplicación de los derechos fundamentales.

Un problema parcialmente distinto es si el legislador puede imponer la observancia de determinados derechos fundamentales en ciertas relaciones privadas. La ley, por ejemplo, prohíbe a los titulares de establecimientos comerciales abiertos al público seleccionar sus clientes por razón de raza. Se da, así, eficacia entre particulares a la prohibición de discriminación del art. 14 de la Constitución; pero obsérvese que esta eficacia entre particulares no nace directamente de la Constitución, sino de la ley. Ello significa que no viene constitucionalmente impuesta, sino que es una opción del legislador, que podría ser modificada por un legislador futuro. Mi opinión es que la ley puede llevar a cabo una política de libertades públicas en el ámbito privado, siempre que ello no vulnere alguna norma constitucional y, en especial, derechos fundamentales de otros. Dicho de otra manera, aquí el problema es de ponderación entre el derecho que se trata de extender por vía legislativa a las relaciones privadas y otros derechos fundamentales con los que pueda entrar en colisión.

\section{ÁNGEL GÓMEZ MONTORO}

Entiendo que la mejor manera de avanzar — de seguir avanzando- en este tema es evitar buscar una solución única aplicable a todos los casos y, más bien, distinguir entre los diferentes derechos e incluso los distintos ámbitos de las relaciones privadas en los que los derechos pueden estar en juego. Cuando se toma este punto de partida, los desacuerdos no son tan grandes como parece deducirse de los análisis teóricos en los que las posiciones siguen estando muy encontradas. En este sentido, considero que la cuestión de la eficacia de los derechos en las relaciones laborales está relativamente bien resuelta (sin perjuicio de que siga existiendo una inevitable litigiosidad cuando se 
trata de resolver cada caso) y en buen medida gracias a las previsiones legales del propio Estatuto de los Trabajadores o de la legislación laboral.

Más problemas sigue presentando la eficacia de ciertos derechos y, en particular, de la igualdad, en relaciones meramente privadas. $\mathrm{Y}$ he de confesar que en este terreno, y a pesar de las razones que se esgrimen en favor de la eficacia inmediata de los derechos fundamentales (tan magníficamente expuestas, por ejemplo, en el libro del prof. Bilbao), sigo siendo partidario de una eficacia limitada, que requiere siempre la mediación del legislador. Comparto plenamente la idea de que los valores que representan los derechos fundamentales deben inspirar también las relaciones entre particulares, pero no creo que ello signifique exactamente que su garantía deba hacerse a través de los derechos fundamentales y, en particular, partiendo de la eficacia directa e inmediata de que gozan frente al poder público. Los derechos fundamentales pretenden, en buena medida, garantizar una libertad que está asimismo en la base de la autonomía privada y de aquí que contraponer los derechos a esa autonomía implicaría en buena medida desvirtuar el propio sentido de los derechos. En estos casos entiendo que la limitación de la autonomía de la voluntad (autonomía que subyace, por cierto, en muchos derechos tales como la asociación, la libertad de empresa, la creación de centros docentes, de medios de comunicación, etc.) exigirá la mediación de la ley aunque esa libertad tendrá siempre el límite de la dignidad de la persona que está en la base misma de los derechos fundamentales: de manera que serán nulas aquellas manifestaciones del ejercicio de la autonomía de la voluntad que supongan discriminaciones especialmente odiosas o conductas denigratorias de la persona.

\section{GREGORIO PECES-BARBA MARTÍNEZ}

Yo daría los criterios más amplios posibles en la interpretación de esa eficacia, superando la vieja idea clásica de que los derechos lo son siempre frente y respecto al poder político.

\section{JUAN JOSÉ SOLOZÁBAL ECHAVARRÍA}

La titularidad de los derechos y la cuestión de su eficacia entre particulares merece alguna consideración que tal vez podría tener reflejo normativo. Por lo que hace a los derechos de los extranjeros no ignoramos que el principal tratamiento de la cuestión debe ser el de la facilitación de la adquisición de la nacionalidad española, hecha posible de acuerdo con la realidad de los nuevos tiempos en los que el futuro corresponderá a sociedades con un fuerte componente, al principio, multicultural y que experimentarán un importante mestizaje. La adaptación a esta situación, en absoluto nada fácil, y que tiene que ver con la exigencia en toda sociedad de un mínimo de integración, a favorecer positivamente mediante políticas de incorporación, en su 
aspecto negativo realza la importancia del límite del orden público constitucional como tope del ejercicio de los derechos de los extranjeros y garantía de la supervivencia efectiva del sistema político español. Quizás entonces no sobraría la constancia constitucional formulada como exigencia universal de la existencia de un límite de estos derechos. Se trataría con todo de evitar un compromiso con la democracia militante o el patriotismo constitucional, pero que expresase efectivamente la base material valorativa de nuestro orden constitucional. Por lo que respecta a la titularidad de los derechos de los extranjeros, creo que el artículo 13 CE debiera sustituir la alusión al reconocimiento de "las libertades públicas" de los extranjeros por una referencia a los derechos y deberes del presente Título I, protegibles de acuerdo con las posibilidades constitucionales. De este modo ni la ley podría desconocer en su esencia los derechos de que disfrutasen los extranjeros, más allá de las libertades públicas, ni cabrían dudas sobre la plena disponibilidad jurisdiccional, en la vía del amparo judicial o constitucional, de los derechos de los extranjeros. Quizás no faltarían razones para establecer constitucionalmente una cláusula de mejor derecho para los ciudadanos comunitarios y para los extranjeros que se encontrasen en situación de plena regularidad.

Como se sabe el texto constitucional guarda silencio sobre los derechos fundamentales de las personas jurídicas fuera del reconocimiento expreso de algunos en cada supuesto concreto, se trate por ejemplo de los derechos de las Confesiones Religiosas, o la libertad de creación de centros o los derechos de los partidos o las asociaciones a su pleno desenvolvimiento en libertad, respecto de los que, como no podía ser de otra forma, las mismas cláusulas prescriptivas aducen lo pertinente. Entonces tal vez podría pensarse en añadir al texto constitucional una cláusula que se refiriese a esta cuestión en términos generales, en la línea de lo que ocurre en la Constitución alemana y ha establecido la jurisprudencia de nuestro Tribunal Constitucional, admitiendo de principio la titularidad por las personas jurídicas de los derechos fundamentales, teniendo en cuenta su naturaleza y los términos de su reconocimiento en la Norma Fundamental. Asimismo podría pensarse en un precepto constitucional que reconociese los derechos fundamentales del menor, excluyendo de los mismos, bien en su totalidad o en lo referido a algunas facultades determinadas a los que pudiesen introducir una responsabilidad patrimonial del menor. Cierto que los derechos fundamentales exigen para su disfrute de una madurez mental que sólo cabe presuponer cabalmente en la mayoría de edad, pero el carácter espiritual de los derechos fundamentales, como facultades ligadas a la dignidad de la persona, puede justificar que las leyes, al menos en el caso de algunos derechos, permitan su ejercicio a los menores, solos o con la ayuda tutorial, y aunque dicha atribución del derecho al menor se restrinja, como digo, a algunas facultades de los mismos. En efecto la legislación sectorial, general o no, reconocerá al menor derechos fundamentales como el de contraer matrimonio o instrumentará determinadas intervenciones procesales para la defensa de los intereses legítimos del menor, acogerá diversas formas de participación del menor en los centros educativos, 
atenderá al derecho de asociación y manifestación del menor o le garantizará la libertad ideológica o la libertad de expresión de acuerdo con estándares que, a la vista de las actuales circunstancias, denoten una mayor capacidad intelectual del, desde un punto de vista constitucional, menor de edad. Sería de desear que estas intervenciones legislativas tuvieran una mínima cobertura constitucional explícita.

\section{NUEVAS PERSPECTIVAS EN LA DOGMÁTICA DE LOS DERECHOS}

$8{ }^{a}$ ¿En que puntos deberia avanzar y profundizar prioritariamente la dogmática de los derechos fundamentales?

\section{LUIS MARÍA DÍEZ-PICAZO}

Me parece que la dogmática de los derechos fundamentales estuvo relativamente descuidada en época inmediatamente posterior a la entrada en vigor de la Constitución. Ello quizá se debiera a que había temas más urgentes, como la construcción del Estado autonómico o la clarificación del sistema de fuentes. En los últimos años, sin embargo, se ha avanzado muchísimo y hoy los derechos fundamentales son seguramente el sector que más jóvenes constitucionalistas recibe. No creo que haya ningún aspecto que, hoy por hoy, merezca una atención especial. Me parece, más bien, que cada uno debe estudiar lo que le interese, siempre que se trate de problemas reales, no de problemas inventados. Y precisamente a este respecto es importante, cuando se abordan temas de derechos fundamentales, huir de la tentación de una excesiva abstracción o, por decirlo más crudamente, de tratar esos temas desde un punto de vista filosófico. No seré yo quien niegue la conexión existente entre el derecho de los derechos fundamentales y la reflexión ética; pero, al final, es una rama del derecho, que debe ser abordada con los instrumentos propios del jurista. Y añadiré aún otra cosa: los derechos fundamentales son la parte del derecho constitucional que es más específicamente nuestra, de los constitucionalistas. Por razones históricas bien conocidas, otras partes del derecho constitucional, como las fuentes del derecho o la organización del Estado, son en gran medida tributarias de lo que ya habían construido los administrativistas. Ello no ocurre en los derechos fundamentales, donde la dogmática ha sido elaborada en los últimos decenios y básicamente por los constitucionalistas.

\section{ÁNGEL GÓMEZ MONTORO}

Desde el punto de vista de lo que podemos llamar la teoría general de los derechos fundamentales pienso que uno de los temas claves sigue siendo la llamada dimensión objetiva de los derechos fundamentales y las consecuencias que de la misma se deriva. En buena medida sigue siendo necesario profundizar y buscar soluciones a muchas de las cuestiones que E. W. Böckenförde 
planteó en su conocido trabajo con motivo de los cuarenta años de la Ley Fundamental de Bonn. En concreto, el entendimiento de los derechos como mandatos de protección (con la exigencia, incluso, de tipificación penal de determinadas conductas contrarias a los derechos), o su concepción como mandatos de optimización para el poder público siguen suscitando problemas que están lejos de ser claros tanto en la doctrina como en las soluciones jurisprudenciales.

En este mismo marco se sitúan las cuestiones relativas a la eficacia de los derechos en las relaciones privadas a los que me he referido en la pregunta anterior y, más en general, la relación entre derechos fundamentales y Derecho privado. Se trata en todos los casos de temas complicados cuya correcta solución pasa, en mi modo de ver, por el correcto entendimiento de lo que son los derechos fundamentales.

Y quisiera asimismo aludir a dos cuestiones más concretas que considero especialmente relevantes en nuestros días. De un lado, la necesidad - a la que antes me he referido- de buscar respuestas correctas a los grandes retos que plantean los avances de la biomedicina o la bioingeniería. Hay muchas y fundadas esperanzas puestas en ellas pero pienso que está extendida una visión utilitarista y pragmática que en ocasiones resulta - o puede resultarpoco compatible con la noción misma de dignidad del hombre que está en la base de los derechos fundamentales tal y como proclama el art. 10.1 de nuestra Constitución. Precisamente por que tales avances deben estar al servicio del hombre no pueden llevarse a cabo a costa de la dignidad de concretos seres humanos y por eso resulta imprescindible determinar los límites de la investigación en tales materias. No me parecen admisibles las cesiones en este terreno - por ejemplo en la investigación con embriones- sobre la base de que todo lo que se puede hacer finalmente se hará o con razonamientos del tipo coste-beneficio, tan propios de un liberalismo que poco tiene que ver con los principios que están en la base de nuestro sistema de derechos fundamentales. En este sentido, y aunque relativa a otro tipo de cuestiones, me parece especialmente valiosa la sentencia del Tribunal Constitucional Federal alemán, de 15 de febrero de 2006, sobre la Ley de Seguridad Aérea, que ha comentado entre nosotros el prof. Rodríguez de Santiago.

Y una segunda cuestión que me parece requiere una especial atención de la doctrina tiene que ver con el entendimiento actual de la igualdad no como un límite al poder sino como una habilitación o incluso como un mandato de intervención del poder público. Un entendimiento en el que es necesario avanzar pero buscando las correctas soluciones jurídicas para evitar problemas como los que ha suscitado, por ejemplo, la tipificación penal de la violencia de género o la adecuada presencia de hombres y mujeres en las listas electorales.

\section{GREGORIO PECES-BARBA MARTÍNEZ}

Creo que en la extensión de la protección jurisdiccional tanto nacional, como, sobre todo, internacional, tanto en Europa como en Naciones Unidas, 
donde la protección es muy débil y rudimentaria. También creo que será necesario avanzar en la búsqueda de contenidos de nuevos derechos fundamentales, especialmente de los llamados derechos específicos que afectan a colectivos que no abarcan a toda la humanidad.

ABSTRACT. It is approached in this survey the constitutional treatment of the fundamental rights. This way, for example, the systematic of the Title I of the Constitution, the nature of the principles rectors or the different approaches of the limitation of rights. 